Pathways for the Oxidation of Sarin in Urban Atmospheres

$$
\begin{gathered}
\text { MEC } \\
\text { DEC } 234998 \\
\text { OSTI }
\end{gathered}
$$


An Affirmative Action/Equal Opportunity Employer

This report was prepared as an account of work sponsored by an agency of the United States Government. Neither The Regents of the University of California, the United States

Government nor any agency thereof, nor any of their employees, makes any warranty, express or intplied, or assumes any legal liability or responsibility for the accuracy, completeness, or usefulness of any information, apparatus, product, or process disclosed, or represents that its use would not infringe privately owned rights. Reference herein to any specific commercial product, process, or service by trade name, trademark, manufacturer, or otherwise, does not necessarily constitute or imply its endorsement, recommendation, or favoring by The Regents of the University of California, the United States Government, or any agency thereof. The views and opinions of authors expressed herein do not necessarily state or reflect those of The Regents of the University of California, the United States Government, or any agency thereof. Los Alamos National Laboratory strongly supports academic freedom and a researcher's right to publish; as an institution, however, the Laboratory does not endorse the viewpoint of a publication or guarantee its technical correctness. 


\section{DISCLAIMER}

Portions of this document may be illegible in electronic image products. Images are produced from the best available original document. 
UC-700

Issued: November 1998

Pathways for the Oxidation

of Sarin in Urban Atmospheres

Scott Elliott

Gerald E. Streit

Jeffrey S. Gaffney*

James E. Bossert

Michael Brown

Jon Reisner

Laurie A. McNair

*Consultant at Los Alantos. Environmental Research Division,

Argomne National Laboratory, Argonne, Illinois.

\section{Los Alamos




\title{
PATHWAYS FOR THE OXIDATION OF SARIN IN URBAN ATMOSPHERES
}

\author{
By Scott Elliott, Gerald E. Streit, Jeffrey S. Gaffney, James E. Bossert, Michael Brown, \\ Jon Reisner, and Laurie A. McNair
}

\begin{abstract}
Terrorists have threatened and carried out chemical/biological agent attacks on targets in major cities. The nerve agent sarin figured prominently in one well-publicized incident. Vapors disseminating from open containers in a Tokyo subway caused thousands of casualties. High-resolution tracer transport modeling of agent dispersion is at hand and will be enhanced by data on reactions with components of the urban atmosphere. As a sample of the level of complexity currently attainable, we elaborate the mechanisms by which sarin can decompose in polluted air.
\end{abstract}

A release scenario is outlined involving the passage of a gas-phase agent through a city locale in the daytime. The atmospheric chemistry database on related organophosphorus pesticides is mined for rate and product information. The hydroxyl radical and fine-mode particles are identified as major reactants. A review of urban air chemistry/microphysics generates concentration tables for major oxidant and aerosol types in both clean and dirty environments. Organic structure-reactivity relationships yield an upper limit of $10^{-11} \mathrm{~cm}^{3}$ molecule $\mathrm{e}^{-1} \mathrm{~s}^{-1}$ for hydrogen abstraction by hydroxyl. The associated midday loss time scale could be as little as one hour. Product distributions are difficult to define but may include nontoxic organic oxygenates, inorganic phosphorus acids, sarin-like aldehydes, and nitrates preserving cholinergic capabilities. Agent molecules will contact aerosol surfaces in on the order of minutes, with hydrolysis and side-chain oxidation as likely reaction channels.

Major uncertainties in our analysis concern the inductive influence of fluoride on electron distributions and hydroxyl rates, the particle sticking coefficient, and the rate of aerosolphase losses. Potential products vary widely in toxicity and persistence. Molecular modeling could shed light on the hydroxyl rate constants. Atmospheric chemistry-style laboratory approaches could be used to enrich understanding of kinetics and mechanisms. Both vapor-phase and surface chemistry experiments are envisioned. Sarin decay schemes 
will soon be inserted into high-resolution models of urban air transport but may require full coupling with photochemistry. Because the nerve agent terrorism issue is immediate and civilian in nature, our research derives mainly from the open scientific literature. Meshing our results with defense sources is the next priority. 


\section{Introduction}

The threat of terrorist release of chemical or biological warfare agents has become a fact of modern life in cities of the developed world. Attempts have been made to spread sarin and anthrax in high-profile capitals (TSSI, 1997; Marshall, 1997). Hoaxes have been perpetrated as well as but only serve to heighten awareness that terrorist attacks could become real. A handful of relevant incidents is documented in Table 1. The major economic zones of the northern hemisphere have all seen exposure. Full mobilization of local emergency and security forces tends to be a response minimum. There is general agreement that effective terrorist attacks with chemical/biological agents could lead to large loss of life and property in urban centers (Department of Commerce, 1994; TSSI, 1997).

The likelihood of chemical/biological terrorism has led several groups of scientists to study agent dispersion in the urban environment. For example, our colleagues around the Department of Energy complex are planning a tracer-transport-type simulation of releases in urban microscale models (Daisey et al., 1997). For some of the agents, intricate transformations will take place in the complex physicochemical arena of the urban atmosphere. Photochemical decay will produce an array of intermediates, some of which will themselves be dangerous and may be more persistent than precursors. The enormous variety of urban oxidants and organics, from both the gas and particulate phases, can serve as reaction partners along the destruction sequences (Finlayson Pitts and Pitts, 1997). To illustrate the scope of these issues, we have elected here to elucidate degradation pathways for the nerve agent sarin, also known as GB (Harris et al., 1982; Gunderson et al., 1992). Sarin is selected for numerous reasons:

(1) It is one of the few chem/bio agents that has actually been released during peacetime into a major urban zone (Table 1; Ember, 1995).

(2) Recent military applications have been substantiated in several parts of the world (United Nations, 1986; McCarthy, 1997).

(3) The chemical structure is similar to a class of organophosphorus pesticides (Zapf, 1993) for which the atmospheric chemistry has been partially investigated (Atkinson et al., 1989; Winer and Atkinson, 1990).

(4) Although sarin transformations in the urban atmosphere will be very involved, they are more amenable to quantification than those of biological agents; urban air chemistry and physics are developed fields. 
We take as our goal here the definition of uncertainties in channels for sarin breakdown within the air of modern cities. The conceptual techniques we will use include estimation of gas-phase rate constants through energy correlation and particle contact rates from surface area models. The methods are strongly grounded in current urban atmosphere chemistry studies. For example, they have been applied across the spectrum of vapor and condensed organics. A short list of the hydrocarbon gases so analyzed might hit upon the major olefinic species (Atkinson and Carter, 1984; Atkinson and Lloyd, 1981; Paulson and Seinfeld, 1992). As a sample of the level of intricacy which can be faced, schematics for permutations of the gas phase of propylene and isoprene oxidations are offered in Figures 1 and 2. Sarin is a heavier, more complex molecule. Large organics and their oxidation intermediates will interact with the aerosol system by virtue of low volatility. The role of secondary species in formations of urban particles has been topical over several decades and constitutes another worthwhile analog (Grosjean and Friedlander, 1975 and 1980; Grosjean et al., 1978; Pandis et al., 1993; Odum et al., 1997). A major contribution to the carbonaceous fraction of the aerosol comes from multifunctional hydrocarbon oxygenates, which tend to be generated during breakdown of ring structures. Products from smogchamber-type experiments on several double-bonded cyclics and an aromatic are listed in Figure 3.

The focus of the present work concerns bulk gas-phase and aerosol properties of the sarin nerve agent, along with those of its photochemical progeny/reactants. Our thinking is that transport, and also boundary activities such as deposition, will be covered during coupling to fluid dynamics models. We will adopt the open, mainstream scientific literature as our initial departure point. The intent is to generate quickly a useful and verifiable reaction/transformation catalog; our feeling is that time may be of the essence. The Stockholm International Peace Research Institute (SIPRI) (see Robinson, 1980) has taken a similar position in considering destruction of chemical weapons stockpiles. A search of unclassified sources has been completed and constitutes the basis for our work. It is of course only fitting that military publications on the weapons of mass destruction should be more difficult to obtain and filter. We are still compiling references from less accessible defense archives. It is as yet unclear that this information can be incorporated, but our plan is to update the mechanisms when and if it becomes possible. An auxiliary argument can be cited for beginning with peer-reviewed journals and standard sources; military and defense documents on sarin behavior tend to stress battlefield conditions (Hoeber and Douglas, 1978; Robinson and Trapp, 1991). Our task here is to translate to the urban atmosphere. 
Our text begins by providing background information on the nerve agents as a class of organic molecules, and on sarin in particular. Some anecdotal information is given on military and accidental applications over the several decades since development. The recent release of sarin on a Tokyo subway line is then described in detail (Ember, 1993; Ohbu et al., 1997; TSSI, 1997). From the attack profile we construct a potential scenario for a terrorist sarin attack which involves significant photochemistry and aerosol physics. Next, the chemistry of related pesticides is reviewed. The combination of their relatively high toxicity and importance to domestic agriculture have garnered much attention for their atmospheric transport and transformations. It becomes clear that oxidation of toxic substances in the atmosphere can lead to activation (Lewis and Lee, 1976; Wolfe and Seiber, 1993; Seiber and Woodrow, 1994), and useful reactivity data are gained for organophosphorus compounds (Winer and Atkinson, 1990). General physicochemical features of urban atmospheres are also described. Portraits are sketched of the oxidant and particulate fields typical of city air (Finlayson Pitts and Pitts, 1997).

Eventually, major sarin release mechanisms and breakdown pathways are outlined. Emphasis is placed on gas-phase oxidation reactions because crude rate estimates can be deduced through classical structure-reactivity relationships (e.g., Gaffney and Levine, 1979; Heicklen, 1981). Time constants for diffusion to aerosols are estimated as well in order to place limits on losses taking place through the variety of heterogeneous processes available.

Conclusions resulting from these exercises can be summarized as follows. We estimate rates for reactions of sarin with major urban oxidants such as the hydroxyl radical and ozone and also for direct photolysis. Comparisons with structural groups in related molecules suggest that the dominant gas-phase decay channel will be hydroxyl attack on the interior hydrogen of the isopropyl group (Winer and Atkinson, 1990). Methyl hydrogens more distant from the oxygen atom linkage to phosphate are numerous but may not be strongly activated through induction. During sunlit periods, the first abstraction may occur with a time constant on the order of an hour. However, large uncertainties in hydroxyl rate and in oxidant concentrations suggest an upper limit of more than a day. Removal of the interor hydrogen atom may lead to production of a three-carbon oxygenate such as acetone and phosphate species similar to sarin hydrolysis products (Verweij et al., 1979). Other decomposition yields are possible. Attack of hydroxyl on the methyl groups will lead to aldehydes and nitrates through channels which are known standards in atmospheric chemistry (Finlayson Pitts and Pitts, 1997). Because the structures will be sufficiently 
close to that of the parent nerve agent, toxicity is a concern. A key in the transfer of toxicity down the oxidation sequence is retention of a fluorine atom/fluoride-leaving group (Metcalf, 1982). Hydroxyl may also add to the central phosphorus atom. We have thus far been unable to estimate the rate, but it is unlikely to exceed that for overall abstractions. Contact with the surface of the aerosol is faster than gas-phase oxidation, but real mass transfer cannot be estimated because reaction rates in and on particles are unknown. Products of hydrolysis or nucleophilic substitutions (Harris et al., 1982; Metcalf, 1982) in particle aqueous phases may be safe, but if sarin is stable in the slowly depositing fine fraction, long range transport is facilitated (Seinfeld, 1986). Ozone reaction and photolytic decay are probably slow processes. Coating of particles by secondary organics complicates phase transfer.

In the final section of the text we discuss some ramifications and extensions of our findings. The potential is assessed for coupling of our sarin chemistry and its attendant uncertainties into a new generation of urban microscale flow programs (Daisey et al., 1997). A major assumption made in our initial portrait of vapor phase channels is that a sarin injection does not alter oxidant concentrations. In fact, local nonlinearities may influence hydroxyl in the near field, and the effect is ripe for microchemical simulations. Techniques for reducing error bars in our rate estimates are itemized. We can envision more sophisticated exploitation of the structural correlations with gas-phase rates as well as experiments in the laboratories of urban atmosphere chemistry. The latter work could encompass both gas phase and heterogeneous transformations (Finlayson Pitts and Pitts, 1997; Ravishankara, 1997). A problem is that lab work on nerve agents will be even more tedious than the study of customary reactions (Zapf, 1993). It may be quite some time before the open chemistry community could generate useful rate data. Again then, we may be led to consider the defense literature and research establishment resources.

\section{The Nerve Agents and Sarin}

Full chemical structures for some of the organophosphorus nerve agents are given in Figure 4 (Department of Commerce, 1994), with schematic forms appearing in Table 2 (Verweij et al., 1979). The latter illustration also clarifies the close structural relationships with pesticides such as parathion and malathion. The agents sarin, soman, and VX may be thought of as derivatives of methylphosphonic acid, the pesticides of common phosphoric 
acid or its thion (double-bond S) analog (Verweij et al., 1979). Note that tabun does not contain the phosphorus methyl group.

The compounds are termed nerve agents because of their catastrophic effect upon the human nervous system (Harris et al., 1982; Robinson, 1992). The central P atom is capable of phosphorylating the esteratic site of the enzyme cholinesterase (ChE); it can react there to produce a phosphorus ester. The enzyme thus constrained is irreversibly inhibited. It can no longer remove the neurohormone acetylcholine ( $\mathrm{ACh}$ ) from the synapse region between nerve cells. Accumulation of ACh blocks normal nervous function. The symptoms are termed cholinergic and include nausea, ocular pain and dysfunction (Rengstorff, 1985; Nohara and Segawa, 1996; Kato and Hamanaka, 1996), convulsions, coma, and death (Foye, 1975; Metcalf, 1982). The nerve compounds constitute a subset of the more general family of organophosphorus cholinesterase inhibitors, which includes pesticides (Gearien, 1982). The basic effects such as tremors, convulsions, and paralysis are common to all higher organisms and also to insects (Metcalf, 1982). There are longer term human symptoms of nerve gas exposure classified as noncholinergic (Jamal, 1995; Ishikawa, 1997). Carcinogenicity is a possibility. Investigations of the Gulf War syndrome suggest that chronic low exposures can affect memory (Wickelgreen, 1997).

Normal ChE function (A) and the mode of inhibition (B) are both shown in Table 3 (Fest and Schmidt, 1973; Metcalf, 1982; Foye, 1975). The initial reactions in each sequence amount to the well-known $S_{N} 2$ process (bimolecular nucleophilic substitution); they can be interpreted as the replacement of a free ester with an active site ester. From the enzyme standpoint, a nucleophilic serine hydroxyl group attacks an electrophile entering the interior of the protein secondary structure. Support is provided by an imidazole ring attached to a neighboring histidine residue and by dicarboxylic amino acids as well. With acetylcholine as the electrophile, an initial equilibrium hold is established between one of the carboxyl groups and the positively charged nitrogen atom (Gearien, 1982). The free ester is then broken apart by serine.Water restores the original enzyme form and yields acetic acid. The hydrolysis is complete within microseconds.

The cholinesterase inhibitors come equipped with $\mathrm{S}_{\mathrm{N}}$ 2-leaving groups. The serine hydroxyl displaces this substituent. But hydrolysis to return enzyme functions is a slow process, perhaps requiring days. Factors determining the degree of inhibition include the electrophilicity of the phosphorus center, the strength of the P-X bond, and substituent steric effects. Details of the overall esterase mechanism, such as the nature of hydrogen 
transfer, remain controversial (Gearien, 1982). In most proposed schemes the transition state bears the form $\mathrm{CH}_{3} \mathrm{EC}\left(\mathrm{O}^{-}\right) \mathrm{OR}$. For the nerve agents the $\mathrm{ChE}$ reaction is sometimes used as a sensitive mode of detection (Lundin, 1968 and 1976). Self-injection of antidote has been developed as a safety technology by the military (Dunn and Sidell, 1989). The antidotes are chemically configured to hydrolyze the phosphorus ester.

The cholinesterase inhibitors as a class were discovered in the 1930s through the chance observation of cholinergic effects of diethyl phosphorofluoridate in humans (Metcalf, 1982). The sarin structure, termed isopropyl methyl phosphonofluoridate, is quite close to this original precursor. Nerve agents were in fact developed before the OP pesticides, in part because of the adequacy of existing biocontrol methods. Germany possessed considerable capabilities before 1940 (SIPRI, 1980). The agents were not used in World War II, but considerable energy has since been devoted to update the early Geneva convention to accommodate them (SIPRI, 1980; United Nations, 1986). In weapons manuals, explosion is often recommended for the dissemination of agent droplets (Rothschild, 1964; Dunn and Sidell, 1989). Actual military applications have been limited (Hoeber and Douglass, 1978). Iraq probably spread sarin and other agents over Kurdish towns in the 1970s (Ember, 1993), and analytical evidence points to its use in the Iran and Gulf wars (United Nations, 1986; McCarthy, 1997). Accidental exposures may be more numerous (SIPRI, 1980; Rengstorff, 1985, Nozaki et al., 1995). Serious efforts have been made to study contact with the chemical agents which may have occurred in connection with their production in the Axis countries of World War II. It has been established that the U.S. Air Force mistakenly dumped large quantities of $\mathrm{G}$ agents on pastoral lands near Salt Lake City, Utah, during the Cold War (Hoeber and Douglass, 1978). As many as 10,000 sheep may have died as a result.

Physical properties of the nerve agents have been compiled many times (e.g., Vojvodic and Binenfeld, 1980; Rothschild, 1964; U.S. Army, 1975; Harris et al., 1982). A summary is provided in Table 4 . The compounds are clear or lightly colored yellow brown liquids at room temperature. Note that their relative volabilities could be predicted in part from their molecular weights. Substituent's effects also enter in, of course. The consistency of some of the liquids is roughly that of gasoline. As might be expected, then, a spill on the ground results in rapid evaporation. Sarin is among the more volatile of the $\mathrm{G}$ agents. The major environmental loss process which has so far been considered for sarin is generalized hydrolysis in aqueous media and on moist surfaces (Figure 5). Hydrolysis products were the substances identified in bomb craters at Kurdish villages several years after the original 
Iraqi attacks (Ember, 1993). As a means of detection, hydrolysis can be forced, then followed by derivitization to increase volability (Verweij et al., 1979). Basic solutions are most effective and can be used in decontamination procedures, although the simple expedient of permitting evaporation works as well (Rothschild, 1964). Handy points of reference are the following: sarin decomposes in one or two days in room temperature distilled water and is most stable in the $\mathrm{pH}$ range 4-6.5 (Harris, 1982).

Many experts today believe that terrorists have pushed conventional weapons to the limits of usefulness and that chemical and biological warfare agents represent the future for rogue political activities. Chemical weapons are at their most effective when deployed against untrained personnel because within the realm of the military, antidote and protective technologies are well-developed. Both average citizens and first respondents are at risk in today's cities. Nerve agent production represents a nontrivial endeavor for small terrorist groups (Mikulak, 1980; Zapf, 1993). Air-tight synthesis areas and elaborate personal protection equipment are preferred. However, the recent release of sarin by a cult in Tokyo demonstrates considerable feasibility (Ember, 1995). The production was apparently carried out inside a standard laboratory fume hood.

The Tokyo release will serve as the foundation for our model scenario here, and we will describe it in some detail. Our information is gleaned from medical, counter-terrorism, and news sources made public shortly after the the story broke (Ember, 1995; Okumura et al., 1996; TSSI, 1997; Yasuda et al., 1997). An extremist political/religious group sponsored the sarin synthesis. The agent was placed in small paper bags, which were left open and set inside subway cars. Direct contact was made with the liquid by janitorial staff, and this led to rapidly to a handful of deaths. Dispersal of sarin in the vapor phase caused ocular and other nonfatal cholinergic symptoms in thousands of individuals. At least 5,000 people were admitted to area hospitals. Inhalation was likely the major mode of entry. Both early diagnoses and later chemical analyses confirmed the identity of the agent. The potency of sarin as a cholinesterase inhibitor is underscored by the huge casualty count.

We propose now a reasonable generic scenario for a terrorist release of nerve agent which couples a likely modus operandi with the potential for significant atmospheric photochemical transformations. Tokyo shows that sarin is a weapon of choice. This is probably because of its toxicity and relative ease of production. Simple explosives could readily have been employed to disseminate droplets, but they were not used. Sarin is known to act as an effective $\mathrm{ChE}$ inhibitor after passage through vapor phase. Furthermore, 
even after the creation of droplets through a detonation, evaporation would lead to casualties. We focus, then, on vapor-phase transport and transformations. The Tokyo release took place in daytime. Terrorists seek broad television coverage of their acts, and daylight optimizes the visual imagery. We study a hypothetical outdoor attack. Indoor release is of course a possibility, but photochemistry will then be limited. Intermediate situations can be envisioned such as dispersal on a train platform. In an area that is well ventilated with free urban air, the arguments we construct remain relevant. If we restrict ourselves to outside incidents, a morning release may be anticipated. Natural light is present, but prior to the lifting of the low nocturnal inversion layer, vertical mixing is minimized. We assume that although wet removal is efficient for the nerve agents and related compounds are efficiently washed out of the atmosphere (Lewis and Lee, 1976), rain is not a factor. Terrorists are likely to consult daily weather reports for planning purposes.

Some miscellany can be mentioned to end our section on sarin itself. It will be of interest to atmospheric and physical chemists that some of the organophosphorus nerve agents exist in stereoisomeric forms which can be separated chromatographically (Smith and Schlager, 1996). Molecular orbital theory has been used to investigate the toxicity of a series of agents and related compounds. Politzer and Jayasuriya (1986) have performed calculations on sarin with replacements for the fluorine substituent in an attempt to pinpoint analogs of lowered toxicity which would nonetheless permit the formation of antibodies.

\section{Related Pesticides}

The organophosphorus pesticides which we will study for guidance are extremely varied in their structures, toxicities, vapor pressures, and other properties. The skeleton in Table 2 can be permuted at both the organic $\mathrm{R}$ substituents and at the leaving group $\mathrm{X}$. Variation has been a key to the commercial success and current widespread application of the OP compounds (Zabik and Seiber, 1993). The chemistry can be tailored to adjust volatility, stability in the environment (hydrolysis is the usual emphasis), and effectiveness against insects. It has been estimated that at least ten million toxic species of the Table 2 form could be synthesized (Metcalf, 1982). Structures of the most common are illustrated in Figure 6. The major biological effects are as discussed above for cholinesterase inhibitors in general (Schrader, 1963; Zapf, 1993). Crucial factors in the inhibition process remain the ability of 
the phosphorus atom to esterify in the ChE active site, and the willingness (or otherwise) of the leaving groups. Vapor pressures have been reviewed by Taylor and Spencer (1990).

A vital distinction between the OP nerve agents and pesticide compounds should be highlighted early on. As shown in Table 2, there are two major pesticide structures with phosphorus double bonded to a sulfur or to an oxygen atom. These are known respectively as the thion and oxon forms (Glotfelty et al., 1987; Wolfe and Seiber, 1993). The thions are the more widely used. Since their central phosphorus sites are less electrophilic than those in the oxons, they are relatively nontoxic (Metcalf, 1982). The thions are ingested by insects and then hydrolyzed to the oxon (activated) within the gut. However, oxidation to oxon can also take place in the atmosphere prior to consumption (Klisenko and Pismennaya, 1979; Atkinson et al., 1989). Lower electrophilicity also means that the thions hydrolyze more slowly in the environment (Seiber et al., 1989).

Early research on insect control substances tended to emphasize first the chemical synthesis-structure issues (Schrader, 1963), then engineering details of application (Lewis and Lee, 1976; Metcalf, 1982). Atmospheric transport and transformations were important only commercially as losses of commodity. Dissemination methods were therefore refined to a degree. In one group of techniques liquid sheets are ejected from specialized spraying devices, then break down into filaments and finally drops. Crop dusting aircraft can be used for efficient delivery (Lewis and Lee, 1976; Metcalf, 1982). The droplet size and distribution is often optimized to around $30 \mu$ to minimize drift. The pesticide compounds can be mixed with oils to reduce evaporation. In an interesting parallel to the Utah nerve agent incident, the collision of two crop dusters in Colorado once mistakenly released large quantities of pesticide aerosol onto grazing land (Lewis and Lee, 1976). In this case it was cattle that were poisoned.

In the 1960 s, it began to be recognized that pesticides were subject to long range transport, with serious human and ecological ramifications. A complex sequence of evaporation, revolatilization, and resuspension steps is involved (Woodrow et al., 1983; Woodrow et al., 1986). Early concerns revolved around DDT and its decay products (Cory et al., 1970; Metcalf, 1982), and it rapidly became clear that they were sufficiently stable to mobilize on the regional scale (Wania and MacKay, 1993). Programs for extensive environmental monitoring were established (Kutz et al., 1976). 
As the OP substances have increased in popularity, so has the number of studies of their fate (Smith et al., 1978; Woodward et al., 1990; Sanders and Seiber, 1984). Human level concerns range from risk of local long term exposure to acute accidental contact by farm laborers (Wilson et al., 1985; Woodrow et al., 1990; Brown et al., 1993). Parallels between anecdotal descriptions of memory loss in agricultural workers and in veterans were among the original pieces of evidence for chronic effects from Gulf War exposure to the nerve agents (Wickelgreen, 1997). Large scale effects on natural ecosystems are possible (Wilson et al., 1991). The agricultural network in California's central valley has perhaps received the closest scrutiny. The OP pesticides have been observed at high concentrations in tule fogs there (Glotfelty et al., 1987 and 1990; Schomberg et al., 1991). Foothills of the Sierra Nevada mountain range appear to be strongly impacted (Cory et al., 1970; Woodrow et al., 1990; Aston and Seiber, 1996). It has been realized that parts of Yosemite National Park and the scenic valley of the Merced River were sprayed directly in the fifties and sixties (Cory et al., 1970). The organophosphorus compounds, their oxon oxidation intermediates, and smaller decay products have been measured in or on organisms at several major trophic levels. Example species include the crops themselves, grasses, pine trees, amphibians, and the red-tailed hawk.

Much progress has been made in the understanding of surface processes in pesticide cycling, and the organophosphorus species have not been excluded. Deposition and resuspension are now thoroughly parameterized (Spencer et al., 1973; Nash and Beall, 1977; Seiber et al., 1979; Woodrow et al., 1986; Woodrow et al., 1990). Standard eddy methods have been adapted to estimate fluxes (Majewski et al., 1989; Taylor and Spencer, 1990). Transfer across the water-air interface can be related to a series of known vapor liquid equilibria (Lewis and Lee, 1976; Sanders and Seiber, 1984). Investigation of atmospheric chemical transformations has been less complete, but is of value to us here as we attempt to define loss mechanisms for sarin.

For the nerve agents, most of the information available on chemistry transport is military in origin. Very little atmospheric chemistry has been dealt with in the open literature. The closely related OP pesticides, while understudied, provide at least a starting point. An early reference to pesticide transformations comes in Smith et al. (1978). Methyl parathion photolysis and hydrolysis rates are given along with a discussion of biodegradation. The term photolysis may refer to overall photolytic decomposition. Klisenko and Pismennaya (1979) identified a major oxidation reaction for the thion phosphorus esters as conversion to oxon, but they did not speculate on a mechanism. Woodrow et al. (1977 and 1983) 
placed chemical conversions in air in the context of long range transport and called for study of rates and reactions. These authors performed gross studies of major oxidation paths for parathion. Their concepts are illustrated in Figure 7. Broad spectrum lamps were used for laboratory photolysis experiments. Elementary steps were not elucidated. Woodrow and coworkers listed their major conclusions as (1) parathion is removed from lower tropospheric air in about ten minutes during the day and (2) the presence of ozone is crucial to any loss reactions (Table 5). Finlayson Pitts and Pitts (1986 and 1997) have since speculated by analogy with simple aromatics such as benzene and toluene (Davis et al., 1975; Hansen et al., 1975; Tully et al., 1981) that hydroxyl radical addition to the conjugated ring structure may have ejected p-nitrophenol (Figure 8). The compound has been observed in many environmental samples. Under some circumstances ozone and the hydroxyl may be correlated, but the possibility of direct ozone reaction with the thion does not appear to be precluded.

Exact mechanisms for thion ester pesticide decay remain unclear to the present day (Finlayson Pitts and Pitts, 1997; Atkinson et al., 1989). Note however that since sarin is an oxon, the details prior to oxidation of the P-S bond are not strictly relevant. Wolfe and Seiber (1993) and Seiber and Woodrow (1994) state that despite the lack of mechanistic information, it is clear many atmospheric breakdown products of the pesticides are highly toxic. Other authors make this point in different forms (Coats, 1990). For example, Metcalf (1982) discusses the possibility that close oxidation derivatives of the cholinesterase inhibitors are toxic. He reminds his readers that the first OP pesticide was the symmetrical species tetraethylpyrophosphate.

In the late 1980s atmospheric kinetics experiments were applied to compounds serving as models for the atmospheric behavior organophosphorus species. Tuazon et al. (1986) measured the rate of reaction for the hydroxyl radical with trimethylphosphate (TMP). Winer and Atkinson (1990) extended this work to a series of thion and other sulfur substituted TMP analogs. Some of the results are reproduced in Table 6 . The values will be discussed in depth below, in light of induction effects along the carbon chains of a variety of organic molecules. The two kinetics groups also investigated direct photolysis of the model species and reactions with ozone. Photolysis was in.general slow. All ozone rate constants were less than or equal to $3 \times 10^{-19} \mathrm{~cm}^{3}$ molecule ${ }^{-1} \mathrm{~s}^{-1}$. Reactions were also conducted with the nitrate radical, but it is most important at night. Our standard sarin scenario spans morning to midday. The rate constant for an $\mathrm{NO}_{3}$ reaction with trimethyl phosphate was less than $10^{-15} \mathrm{~cm}^{3}$ molecule ${ }^{-1} \mathrm{~s}^{-1}$. A rough average nocturnal nitrate 
concentration is $3 \times 10^{8}$ molecules $\mathrm{cm}^{-3}$, so that the associated removal constant is many days in any case. Winer and Atkinson (1990) single out hydrogen abstraction by the hydroxyl as the major atmospheric loss channel for most of the organophosphorus pesticides. Thions were converted to oxons with a yield of around 10\%, perhaps explaining results such as those of Woodrow et al. (1983) or Seiber et al. (1993). Product identification in the studies was restricted to measurement of oxons (Atkinson et al., 1989). The fate of the majority of the pesticide analogs is unknown.

Near surface hydroxyl concentrations are on the order of $10^{6}$ to $10^{7} \mathrm{~cm}^{-3}$ expressed as an average during daytime in mid-latitude agricultural areas (Winer and Atkinson, 1990). Thion pesticides are thus expected to be short-lived (on the order of hours). Recent field work is somewhat consistent with the expectations, but there are indications that extrapolations from the analogs carry a level of uncertainty. For example, Brown et al. (1993) recorded malathion decay in a few days. Models of the pesticide chemistry/transport remain primitive. Teske et al. (1996) inserted a parameterized expression for a droplet size distribution with settling into a Gaussian plume dispersion model. Microphysics, evaporation, and chemistry were not included.

\section{The Urban Atmosphere}

Studies regarding the dispersion of chemical warfare agents in the atmosphere have come mainly from the military perspective (United Nations, 1986; Dunn and Sidell, 1989; Shih et al., 1991). Battlefield situations of the last few decades have been distant from major cities and therefore from their air quality problems and specialized pollutant's personalities. Most known civilian releases fall under the heading of accidents associated with military/industrial production (Kurata, 1980; Lohs, 1980). Connections with the details of atmospheric chemistry have been minimal (e.g., Ministry of Foreign Affairs of Finland, 1985), and we have located no information on the rich set of transformations which are conceivable in urban air.

We now undertake a brief review of photochemistry and aerosol microphysics in the city environment in order to fill in some of these voids. Our motivation is to identify the major reactants among vapor-phase oxidants and across the particle spectrum. The trimethyl phosphate and pesticide analog kinetics (Winer and Atkinson, 1990) suggest that gas-phase species most reactive with sarin will be the hydroxyl radical and ozone. Their 
concentrations in modern cities will be much higher than in the free continental troposphere or in air near agricultural centers. Transfer of the pesticides to particles other than fog/cloud droplets (Glotfelty et al., 1987) has not drawn attention. However, it is again the case that urban concentrations of interactants will be high, expressed as number densities or available surface area. Our treatment will lead to a table of midday levels for major oxidants and particles to give rates for sarin loss pathways. We will rely heavily on our own studies of two important modern mega-urban areas, Los Angeles and Mexico City (e.g. MARI, 1994; Elliott et al., 1997a and b). They will function as examples of polluted atmospheres in the first and developed worlds.

Excluding remote marine areas where nitrogen oxide $\left(\mathrm{NO}_{x} \cong \mathrm{NO}+\mathrm{NO}_{2}\right)$ mole fractions fall below $10 \mathrm{pptv}$, the chemistry of the earth's troposphere can be considered a slow combustion process producing a broad spectrum of oxidants (Crutzen, 1973 and 1988). Organics sourced from the biosphere decompose in the presence of molecular oxygen to give water and $\mathrm{CO}_{2}$ as ultimate products. Intermediates of note are ozone and the hydrogen oxide radicals $\left(\mathrm{HO}_{\mathrm{x}} \cong \mathrm{OH}+\mathrm{HO}_{2}\right)$. The nitrogen oxides catalyze the $\mathrm{O}_{3}$ generation by breaking organic peroxy radical O-O bonds. $\mathrm{RO}_{2}+\mathrm{NO} \rightarrow \mathrm{RO}+\mathrm{NO}_{2}$ and the $\mathrm{NO}_{2}$ photolyzes to yield atomic oxygen which promptly combines with $\mathrm{O}_{2}$. Along the organic oxidation sequences hydrogen atoms are removed by oxygen to form $\mathrm{HO}_{2}$ and augment $\mathrm{HO}_{x}$ levels. Sunlight initiates the entire process by photolyzing ozone to give the highenergy atom $\mathrm{O}^{\mathrm{ID}}$. The excited oxygen attacks water vapor to give two hydroxyl radicals and these are capable of extracting hydrogens from alkanes. Hydroxyl can also begin the breakdown of unsaturated hydrocarbons through addition of double bonds; ozone can add across them (Finlayson Pitts and Pitts, 1997).

Simpler organics tend to be longer lived and so dominate the photochemistry in nonurban areas. Methane and ethane are prominent examples (Blake and Rowland, 1986 and 1988). They survive in the atmosphere for months or longer on a global average basis, but although the initial hydroxyl attack is slow, much of the subsequent decomposition occurs on a time scale of hours to days. Contributions to global oxidant budgets are significant (Singh and Zimmerman, 1992). The methane destruction series is summarized in Table 7 for moderate $\mathrm{NO}_{\mathrm{x}}$ conditions. Fundamental steps producing hydrogen oxides and ozone are similar for larger hydrocarbons. They are reviewed in references such as Crutzen (1988), Jacob et al. (1989), and Elliott et al. (1996). The variety of organics becomes much richer moving toward the major input areas of forests and cities (Singh and Zimmerman, 1992). The molecules also increase in size and complexity. The figures and tables in evidence in 
our introduction here offer some feeling for the level of detail which must be considered. It is convenient to group all the species possessing $\mathrm{C}$ atom skeletons together and refer to them as nonmethane hydrocarbons, or NMHC.

Sources of the nitrogen oxides tend to correspond geographically with and scale to. emissions of NMHC (Liu et al., 1987; Penner et al., 1991). $\mathrm{NO}_{\mathrm{x}}$ is emitted by productive ecosystems and created through equilibration of $\mathrm{N}_{2}$ and $\mathrm{O}_{2}$ with $\mathrm{NO}$ at the high temperatures of the internal combustion engine. Ozone production tracks the $\mathrm{NO}_{x} / \mathrm{NMHC}$ couple, but in a highly nonlinear fashion (Liu et al., 1987; Lin et al., 1988). In the remote marine atmosphere with the $\mathrm{N}$ oxides present at $<\mathrm{ppb}, \mathrm{O}_{3}$ may accrue at ppb per day ( $\mathrm{Liu}$ et al., 1992; Pickering et al., 1993). Similar rates apply as surface $\mathrm{NO}_{\mathrm{x}}$ is convected into the free troposphere during thunderstorms (Pickering et al., 1991). Downwind of major metropolitan areas generation can be in tens of ppb per day (Liu et al., 1987; Elliott et al., 1996). Within cities $\mathrm{NO}_{x}$ may reach hundreds of ppb (MARI, 1994), perhaps a thousand times the concentration in ozone-producing regions of the clean troposphere. Daily ozone production on the other hand, maximizes in the hundred $\mathrm{ppb}$ regime. Part per million $\mathrm{O}_{3}$ concentrations are not observed, even in the most polluted areas. On the global scale the currency of ozone production, which is buildup in a single photoperiod, is often plotted against nitrogen oxide concentrations alone because of the relationship with NMHC (Liu et al., 1987). For urban zones it tends to be visualized in a three-dimensional space against independent $\mathrm{NO}_{\mathrm{x}}$ and organic axes (Dodge, 1977; MARI, 1994). The resulting ozone concentration contours are termed isopleths.

The $\mathrm{HO}_{\mathrm{x}}$ radicals and the hydroxyl in particular are fleeting species present at exceedingly trace levels (<pptv). Naturally, they are very difficult to measure or to simulate. This is true both remotely and in cities. Laser based detection methods have yielded values on the order of $10^{6}$ to $10^{7} \mathrm{~cm}^{-3}$ for $\mathrm{OH}$ in polluted air (Hubler et al., 1984; Hard et al., 1984). Model results are in rough agreement, but uncertainties must be considered large. We adopt here the range for moderate to heavy pollution conditions indicated in the review by Finlayson Pitts and Pitts (1986). More recent work has not altered their conclusions substantially.

Although the photochemistry generalizations we have constructed apply across the global atmosphere and its urban compartments, major cities show strong differences in pollutant character. Urban areas tend to evolve by acquiring people, then wealth, and within a few decades the desire to cleanse themselves. Los Angeles, California, is a much-studied 
megacity lying toward the end of this trajectory. After a period of megapollution effects peaking about 1970 (Seinfeld, 1986; Finlayson Pitts and Pitts, 1997), regulations are beginning to reduce oxidant levels. Mexico City is arguably the world's largest metropolitan area and is still growing rapidly. Pollutant concentrations tend to be several times as large as the Los Angeles experience at its worst, and emissions profiles are quite distinct from the domestic. It has recently been found that leakage of liquefied petroleum gas (LPG) injects large quantities of propane, butane and light olefins into air of the Valley of Mexico (Ruiz et al., 1993; Blake and Rowland, 1995). LPG is used extensively for home heating and cooking. Although both the megacities we deal with owe their serious air pollution dilemmas to their basin-type geography, seasonalities are diametrically opposed. Los Angeles smog is most objectionable in the summer when the sun rises highest in the sky. At $19^{\circ}$ latitude, Mexico City is flush with sunlight all year. Episodes there tend to correlate with winter inversions.

Typical levels for major components of the gas-phase photochemistry system are collected in Table 8. Nitrogen oxide and ozone concentrations are rounded values from Turco (1997) and MARI (1994). NMHC figures are taken from Mayrsohn (1975), Dodge (1977), and Ruiz Santoyo et al. (1993). Most of the species listed undergo strong diurnal cycles. Many are sourced in the morning during the traffic peak, then dilute upward as the nocturnal inversion lifts. Molecules produced by the action of sunlight do not appear until early morning. The likely sarin interactants ozone and hydroxyl fall in this category. Hydroxyl is especially reactive and thus short-lived. It decays quickly in the dark.

The bulk of the urban aerosol is secondary in nature; i.e., it is formed from the condensation of photochemistry products. Gas-phase transformations which yield involatiles thus serve as a conceptual bridge to our discussion of particles. Sulfur dioxide is released into city air through the combustion of impure, fossil carbon fuels (among other mechanisms; Seinfeld, 1986). Sulphur trioxide is formed by the reaction of $\mathrm{SO}_{2}$ with he hydroxyl to form the $\mathrm{HOSO}_{2}$ adduct, followed by an $\mathrm{O}_{2}$ attack to abstract the proton (Stockwell and Calvert, 1983). The trioxide reacts rapidly with ever-present water vapor to form sulfuric acid, which effectively has no vapor pressure. Organic chains containing more than five carbon atoms produce involatile oxygenates as they decompose (Pandis et al., 1992 and 1993). In some cases this is due to sheer size (molecular weight). In others multiple functionality is a factor as when unsaturated rings come apart (Schwartz, 1974; Grosjean and Friedlander, 1980). Most recently it has been demonstrated that the aromatics in whole gasoline vapor produce a large fraction of organics found in particles (Odum et 
al., 1997). Partial combustion products from engine operation also include higher molecular weight hydrocarbons. The exception proving the secondary rule is ammonia. It is produced in the U.S. largely by the cattle in feedlots (Russell et al., 1983; Watson et al., 1994). Cattle are also a major source in Mexico City, but releases are especially voluminous because the sanitation infrastructure is weak. The wastes of human beings and domestic animals including pets and rats are thought to be the most significant ammonia sources.

A reasonable conceptual starting point in understanding the secondary aerosol is the assumption of thermodynamic equilibrium. Gas concentrations in excess of vapor pressures are reduced through phase transformations. The removed portion becomes particulate, and in simple models the changes are instantaneous. The approach is exemplified in the series of codes from Los Angeles, California-based groups (Stelson et al., 1979; Stelson and Seinfeld, 1982a and 1982b; Pandis et al., 1993 Odum et al., 1997). Sulfuric acid is removed immediately and is neutralized by ammonia, which is often in excess (Russell et al, 1983). The remaining ammonia and nitric acid produced from $\mathrm{NO}_{\mathrm{x}}$ equilibrates into ammonium nitrate (Watson et al., 1994). The constant governing removal from the vapor is about $20 \mathrm{ppb}^{2}$ at 20 degrees $\mathrm{C}$. Thus $\mathrm{NH}_{3}$ and $\mathrm{HNO}_{3}$ are able to coexist in the gas phase at the several ppb level. An abundance of one or the other, however, leads to titration. Concentration of the species in excess remains constant while that of the counterpart is lowered to ppb or less. Large and multifunctional organic oxygenates are given a collective vapor pressure of $10 \mathrm{pptv}$, above which they condense. The aerosol becomes a complex internal mixture of inorganic salts and hydrocarbons (Pandis et al., 1992, 1993, and 1995).

Thermodynamic arguments can explain major features of urban aerosol observations. Some gravimetric quantities readily measured on filters are the total suspended particulate (TSP) and respirable suspended particulate (RSP) masses. The two are distinguished by a cutoff at 1 to 3 microns in particle diameter. Large objects sediment under the influence of gravity at greater than 0.1 to $1 \mathrm{~cm} \mathrm{~s}^{-1}$ and su do not penetrate into the lungs. In polluted Los Angeles neighborhoods RSP rises from tens of $\mu \mathrm{g} \mathrm{m}^{-3}$ to on the order of $100 \mu \mathrm{g} \mathrm{m}^{-3}$ over a typical summer morning (Hidy, 1975; Turco, 1997). Condensation of $10 \mathrm{ppb}$ each of ammonia and nitric acid yields $35 \mu \mathrm{g} \mathrm{m}^{-3}$ of ammonium nitrate. Secondary organics are superimposed and can constitute 10 to 30\% of RSP (Pandis et al., 1993). The aerosol system in Mexico City has also been intensely scrutinized through measurements (Aldape et al., 1991a and 1991b, 1993; Miranda et al. 1992 and 1994). The diurnal pattern indicated 
by RSP and visibility data is qualitatively similar. Even at sites in residential areas distant from dust suspension, mass can be several times as large as in Los Angeles. Furthermore, the organic-rich atmosphere of Mexico City is likely to result in higher particle hydrocarbon fractions.

Many refinements to early equilibrium models have been conceived. The ammonium salts are solid under dry conditions but take on water at greater than about 50\% relative humidity. Visibility data and others suggest a rough doubling in particle size (Ho et al, 1974; Tang, 1980a and 1980b). It can be computed that aqueous solutions are formed with ionic strengths on the order of 10 molal. Models for the concentration dependence of activity coefficients can be applied and iterated to minimize the total free energy of the salt system (Saxena et al., 1983; Bassett and Seinfeld, 1983). Dozens of ionic reactions can be included. Sometimes ammonium nitrate and sulfate salts are segregated, while at others mixed salts are incorporated. An essential device in investigations of the atmospheric aerosol is the distribution of particles over a logarithmic distribution of some reflection of size. Aerodynamic diameter is the property usually chosen (Herdan, 1960; Fuchs, 1964; Friedlander, 1977; Lawrence Berkeley Laboratory, 1979). We will bin decadally into the regimes 0.01 to $0.1 \mu$ and 0.1 to $1 \mu$. The two coincide roughly with RSP and provide resolution sufficient for our purposes here. With sizes discriminated, the Kelvin effect can be injected into the equilibrium salt calculations. Surface tension tends to raise partial vapor pressures over smaller droplets (Bassett and Seinfeld, 1984). The net effect is a shift in ammonium nitrate upward through the size series. Sulfate is so low in volatility that it is trapped in the bins of first condensation.

Theories of aerosol dynamics permit us to comprehend the urban size distribution quantitatively and to evaluate its time evolution. RSP objects move through air relative to one another and surfaces in the Brownian sense (through a random walk sequence). Diffusion coefficients have been tabulated to describe the rates (Seinfeld, 1986). Flow of small particles to the surfaces of larger ones can be integrated under the assumption of diffusion control, and the coefficients derived enter into coagulation kernels, which are rate constants for particle collisions (Fuchs, 1964). Objects of diameter $<0.1 \mu$ are created in profusion within the automobile engine and aftermath, as hot saturated vapors cool (Kittelson and Dolan, 1980). The distributions are tight, however, and coagulation leads rapidly into the 0.01 to $0.1 \mu$ regime. Measurements indicate that particle number densities in the 0.01 to $0.1 \mu$ range are on the order of $10^{6} \mathrm{~cm}^{-3}$ near strong roadway sources in Los Angeles (Hidy, 1975; Whitby and Sverdrup, 1980). Coagulation kernels are large and a 
time constant for self-collision is only on the order of hours (Pandis et al., 1995). The particle distribution is skewed further into the 0.1 to $1 \mu$ regime. At this upper end of the RSP, Brownian diffusion rates are low and densities have been reduced by mass balance considerations. Coagulation shuts itself off, and because the chain of events terminates in the 0.1 to $1 \mu$ regime, it is known as the accumulation mode. In Los Angeles particle concentrations drop to about $10^{5} \mathrm{~cm}^{-3}$ over 0.01 to $0.1 \mu$ moving away from major traffic corridors, and are $10^{3} \mathrm{~cm}^{-3}$ as a rule in the accumulation decade. Rough concentrations are placed in Table 8 along with the gas-phase oxidant results derived earlier. At the liquid water density of $1 \mathrm{~g} \mathrm{~cm}^{-3}$, masses are 1 to $20 \mu \mathrm{g} \mathrm{m}^{-3}$ for 0.01 to $0.1 \mu$ and 40 to $80 \mu \mathrm{g} \mathrm{m}^{-3}$ for 0.1 to $1 \mu$ so that consistency is achieved with gravimetry. Larger values in Mexico City are reflected in a factor of two enhancement. In many references size distributions for the urban aerosol are expressed in the volume units $\mu \mathrm{m}^{3} \mathrm{~cm}^{-3}$. As a matter of note here, 1 $\mu \mathrm{m}^{3} \mathrm{~cm}^{-3}$ is identically equal to $1 \mu \mathrm{g} \mathrm{m}^{-3}$ for the liquid water mass density.

The thermodynamic portrait of the aerosol must ultimately be adjusted to account for kinetics. Equilibrium is not achieved instantaneously. Rather condensables make their way to and from particle surfaces at well-defined rates. Two transport regimes must be distinguished. Concentration gradients cannot form above the surface of particles of dimension smaller than the gas-phase molecular mean-free path $\lambda$. At STP the value of $\lambda$ is about $0.1 \mu$ (Pandis et al., 1995). In our 0.01 to $0.1 \mu$ particle bin, gas kinetics describe approach to a particle. The overall constant rate is given by $4 \pi r_{p}^{2} n_{p} 1 / 4 v_{g}$ (Seinfeld, 1986), where $r$ is the radius, $n$ is a number density, and $v$ is the molecular velocity. The subscripts $\mathrm{p}$ and $\mathrm{g}$ signify a particle size bin and the gas partial pressure in the bulk phase. A time constant for efficient removal at the surface is $\tau=\left(4 \pi r_{p}^{2} n_{p} 1 / 4 v\right)^{-1}$. This is conveniently re-expressed in terms of the overall surface area density and an effective directional velocity $1 / 4 \mathrm{v}=\mathrm{v}^{\prime} ; \tau=\left(\mathrm{sv}^{\prime}\right)^{-1}$. A rough value for $\mathrm{v}$ is $300 \mathrm{~m} \mathrm{~s}^{-1}$ in air. The time scale is then 30 seconds at $10^{5}$ particles $\mathrm{cm}^{-3}$ over the 0.01 to $0.1 \mu$ bin. From 0.1 to $1 \mu$ gradients must be accounted for. As for collision/coagulation, flow to individual particles can be integrated through the radius space under the principles of diffusion control (Pandis et al., 1995). The contact rate for instantaneous removal at all surfaces is then $4 \pi r_{p} D n_{p} n_{g}$ where $\mathrm{D}$ is the molecular diffusivity of the vapor $\left(\sim 0.1 \mathrm{~cm}^{2} \mathrm{~s}^{-1}\right)$. The time constant becomes $\left(4 \pi \mathrm{r}_{\mathrm{p}} \mathrm{Dn}_{\mathrm{p}}\right)^{-1}$ and for a density of $10^{3}$ particles $\mathrm{cm}^{-3}$ at 0.1 to $1 \mu$ is again on the order of one minute.

Full theoretical developments for the condensation process incorporate imperfect removal at the surface through the sticking coefficient parameter $\alpha$, and transition near size $0.1 \mu$ from 
the gas kinetic to the continuum regime (Seinfeld, 1986). The theories also account for back flux by defining a gas-phase concentration $n_{s}$ at the surface. Our qualitative results agree with more detailed analyses in references such as Turco et al. (1989) and Pandis et al. (1995). The simplest equation bridging into the continuum is $4 \pi r_{p} D n_{p}\left(n_{g}-n_{s}\right)\left(1+K_{n} /\right.$ $\alpha)^{-1}$ where $K_{n}$ is the Knudsen number $\lambda / r_{p}$ (Turco et al., 1989). This collapses to the kinetic version with a sticking adjustment for $r_{p}<\lambda$. It also extends the transition to larger sizes for small $\alpha$. In other words, if the surface reaction efficiency is small, gradients are negligible even over large objects. Condensation time scales computed explicitly as functions of particle density and size are elaborated in Figure 9 for a sticking coefficient value of 0.1 (Pandis et al., 1995). The constants are a bit longer than for our assumption of unit surface efficiency, but are still in the neighborhood of minutes.

\section{Vapor Phase Oxidation}

From our outline of pesticide atmospheric chemistry, it is apparent that the hydroxyl radical is likely to be a major reactant for the nerve agents (Winer et al., 1990; Finlayson Pitts and Pitts, 1997). Over the suite of organophosphorous compounds studied, including analogs specifically designed for kinetic experiments, interactions with ozone have been slow and direct photolyses undetected. An upper limit rate constant for ozone with trimethyl phosphate was $3 \times 10^{-19} \mathrm{~cm}^{3}$ molecule $\mathrm{s}^{-1}$ at room temperature. In a major city with 100 $\mathrm{ppb} \mathrm{O}_{3}$ present and an overall number density of $2.5 \times 10^{19}$ molecule $\mathrm{cm}^{-3}$, removal requires many days.

While it is occasionally acknowledged in the open literature that hydroxyl may react with the agents, little consideration is given to rate and mechanism. Typical examples of the treatment of atmospheric chemistry for the nerve gases include documents from the Ministry of Foreign Affairs of Finland (1985) and Barden et al. (1993). These references state in a paragraph or so that $\mathrm{OH}$ is a major oxidant and that losses may occur. Time scales and product distributions are not given. We will attempt to improve this situation by drawing on standard techniques developed for estimation of rate constants for hydroxyl attack. We will also consult the broad atmospheric database on organic decay sequences.

A key to the understanding of $\mathrm{OH}$ gas kinetics is recognition that the radical behaves as an electrophile (Gaffney and Levine, 1979; Gaffney et al., 1986). For example, in its addition to organic double bonds, hydroxyl seeks $\pi$-type electrons. As may be expected, then, correlations with electron capture cross sections constitute a predictive tool for $\mathrm{OH}$ attack 
(Gusten, 1984). Bond dissociation energies are less relevant. A classic hydroxyl reaction mechanism is abstraction of the hydrogen atom from a carbon skeleton. Reactivity of a site is determined by the electron donating or withdrawing capabilities of nearby substituents. Donation speeds up the abstraction process; withdrawal slows it down.

Within the sarin structure let us focus initially on the isopropyl group. It can be viewed to first order as a small organic accompanied by a phosphorus ester attachment. The ester in turn may be ether or alcohol-like in its substituent effects. Atmospheric chemists have constructed numerous correlations of hydroxyl rate constants across organic frameworks (e.g., Atkinson, 1987). Log transformation is performed, and the results are sometimes referred to loosely as linear free-energy relationships. The linearity is actually with enthalphy of activation (transition state theory); the term structure-reactivity may thus be preferred. The electron donation and withdrawal influences are strongly in evidence. Organic chemists laid the ground work for explanations of the phenomena in extensive solution phase experiments. In their jargon the communication of kinetic or thermodynamic information along carbon chains is an induction process.

We will now review the structure-reactivity studies briefly, in order to offer credible estimates for the rate of hydroxyl attack on sarin. Atmospheric sources are consulted for the constants themselves. Organic references on inductive effects are sampled to ground our values theoretically. We will work mainly from tabular data. However, it should be noted that modern molecular modeling software permits the individual chemist to probe the electronic distributions of arbitrary molecules. Application of the latest of these programs to the problems of sarin atmospheric chemistry would seem to be timely.

Partial (single) hydrogen atom abstraction rate constants are organized in Table 9 to reflect substituent influences. Sources for the data are Gaffney et al. (1986) and some standard references on atmospheric kinetics (Atkinson ,1986 and 1988; Demore et al., 1990). The trimethyl phosphate data are appended (Winer and Atkinson, 1990). Units in the table are $10^{-12} \mathrm{~cm}^{3}$ hydrogen $\mathrm{s}^{-1}$. The nitrate group is portrayed as a strong electron withdrawer. A rule of thumb is that nitrate and simple fluorides act similarly. The alkyl and oxy-organic compounds are net donors relative to hydrogen. Trimethyl phosphate activates somewhat more strongly. Moving downward through the table it is seen that hydrocarbon side chains enhance abstraction. Data become scarce as the donor/withdrawer moves away from the $\mathrm{H}$ atom of interest. 
Hammett relations developed by organic chemists shed considerable light on the process of electron donation and withdrawal. The experiments on substituted benzoic acid derivatives are best known (Fieser and Fieser, 1961; Roberts and Caserio, 1977). A series of acid dissociation constants is provided in Table 10: Similar trends have been documented for kinetic reactivity and spectroscopic properties of the aromatics. Major results are most obvious for the ortho (first) substitution position. The halogen atoms and $\mathrm{NO}_{2}$ withdraw electrons along the benzene ring and so promote acidity. Note that effects of the methyl and ether groups are ambiguous. In the para (third or opposite) substitution position they reduce acidity, and overall they are nearly neutral against hydrogen. The meta and para substitutions provide the best analogies with Table 9. Positional differences around aromatic rings have quantum mechanical explanations beyond the scope of the present work. Resonance structures can be written as rationalizations and show that pure induction in nonaromatics probably is best modeled by meta compounds. Resonance to the meta location is limited.

The inductive influences have also been documented in solution for straight chain hydrocarbons. Here the alkanoic acids and their halogenates serve as examples, and withdrawal again leads to high dissociation constants. Some approximate pka values for species of the form $\mathrm{XC}(\mathrm{O}) \mathrm{OH}$ are for different $\mathrm{X} ; \mathrm{CH}_{3} \mathrm{CH}_{2} \mathrm{CH}_{2}, 4.7 ; \mathrm{CH}_{3} \mathrm{CH}_{2}, 5.0 ; \mathrm{CH}_{3}$, 4.7; $\mathrm{H}, 3.7 ; \mathrm{ClCH}_{2}, 3.0 ; \mathrm{Cl}_{2} \mathrm{CH}, 3.3 ; \mathrm{Cl}_{3} \mathrm{C}, 1.0 ; \mathrm{CF}_{3}$, strong. The effect scales with the number of halogen atoms. Models describe shifts in the distributions of bonding electrons along the carbon backbone toward the withdrawing substituent. Again the results are consistent with understanding donation/withdrawal and gas phase abstraction rates by the hydroxyl.

Taken at face value, these arguments suggest that the hydrogen atom central to the isopropyl group on sarin will be activated toward the gas kinetic limit. If the phosphorus ester functions as an organic oxygenate, abstraction by the hydroxyl takes place at $10^{-11}$ to $10^{-12} \mathrm{~cm}^{3}$ molecule ${ }^{-1} \mathrm{~s}^{-1}$. The methyl hydrogens are expected to react more slowly, but on the other hand are more numerous and so are favored statistically. A wild card is the fluorine atom attached to the phosphate group. It is a strong electron withdrawer. Note in Table 6 of the pesticide section that oxygen-substituted members of the OP family are less reactive than sulfur counterparts. The sarin molecule is sufficiently unique, however, that structure-reactivity relationships provide little guidance on its fluorine moiety. We are restricted to the establishment of upper limits for the various partial hydroxyl rate constants. 
Likewise, product distributions are difficult to evaluate. The pesticide analog experimenters identified only a small $(\sim 10 \%)$ yield of stable oxon product derived from thion form reactants (Atkinson et al., 1989). All other possibilities remain open. Loss of the central hydrogen in the sarin isopropyl will rapidly be compensated by the attachment of molecular oxygen to form a peroxy radical. In nitrogen oxide-rich urban atmospheres, NO then abstracts one of the paired $\mathrm{O}$ atoms to leave an oxy radical. The steps are illustrated for methane in Table 7 but apply to larger alkanes and alkyl groups as well (Finlayson Pitts and Pitts, 1986; Liu et al., 1987; Jacob et al., 1989, Elliott et al., 1996). The fate of the central alkoxy must be considered highly uncertain. A general guess is that breakage of the C-O-P linkage ensues. The isopropyl group then becomes a benign oxygenate such as acetone. Methyl group rearrangement to the phosphorus fragment is not out of the question. Hydrogen abstraction from the several methyls situated on the molecule results through the standard oxidation sequence in radicals of the form $\mathrm{R}-\mathrm{CH}_{2} \mathrm{O}$. Molecular oxygen removes yet another $\mathrm{H}$ atom from them to produce a family of adehydes. Organic oxy and peroxy radicals are always subject to combination with $\mathrm{NO}_{x}$ to produce nitrates a fraction of the time. The mechanisms are somewhat complex (Finlayson Pitts and Pitts, 1986). Isomerization can accompany the encounter of $\mathrm{RO}_{2}$ with $\mathrm{NO}$, yielding $\mathrm{RONO}_{2}$ (Darnall et al., 1976). The peroxys can simply combine with $\mathrm{NO}_{2}$. The best known example is PAN or peroxyacetyl nitrate (Temple and Taylor, 1983). It is derived from ethane oxidation and is the chief lacrimator in urban smog. The organic nitrates can comprise a major reservoir for $\mathrm{NO}_{\mathrm{x}}$ in polluted air (Singh and Hanst, 1981; Hov et al., 1983; Atherton and Penner, 1988 and 1990). Nerve agent decay could lead in part through nitrate derivatives, especially in the more polluted cities of the developing world. The wide range of product possibilities for the oxidation of sarin in urban environments is illustrated schematically in Figure 10.

Any standard phosphorus acids which arise during sarin decomposition are nontoxic and so are not a concern (Verweij et al., 1979) but where the P-containing fragment retains its fluoride-leaving group danger may remain (O'Brien, 1960). The degree tends to be very uncertain. Analogs to sarin used for laboratory experiments are themselves hazardous (Sivam et al., 1984; Das Gupta et al., 1988; Tripathy et al., 1989; Little et al., 1988 and 1989). Pyrolysis and incineration products maintain a measure of toxicity (Vojeric and Binenfeld, 1980). Entire classes of organophosphorus compounds related to the nerve agents are thought to be potent toxins (SIPRI, 1980; Metcalf, 1982). Some comparisons with the OP pesticides are worth re-emphasizing in the present section. Millions of permutations of the Figure 6 form act as biocides through cholinesterase inhibition (Metcalf, 1982). Pesticide activation during atmospheric decay is not restricted to 
thion/oxon conversion; it extends to the transformation of side chains (Coats, 1990; Wolfe and Seiber, 1993). Risks from exposure to inhibitor oxidation products are poorly defined, whether breakdown begins with nerve agents or commercial chemicals (Boskovic and Kusic, 1980; Jamal, 1995; Ishikawa, 1997; Finlayson Pitts and Pitts, 1997). Some of the more serious symptoms may be long term.

The bulk of the effort in the gas phase oxidation section has been expended on reactions of organic side chains because they are well-known to atmospheric chemists. Inorganic pathways are conceivable, but we have not searched exhaustively for the data necessary to evaluate them. Hydroxyl attack upon the phosphorus atom can be imagined. A methyl group could be displaced. The carbon-to-phosphorus bond tends to be a weak one. At this point, however, consideration of the chemistry of the phosphorus site must be categorized as speculation. A concerted study of the inorganic chemistry of sarin in the atmosphere is yet another option for future research.

Urban concentrations of the hydroxyl radical rise to near the midday maxima in Table 8 within a few hours after sunrise. We thus expect the sarin lifetime against $\mathrm{OH}$ attack to fall over the morning toward a limiting minimum of one hour in confined spaces within highly polluted cities. The fluorine effect is an open matter and means that the removal could be an order of magnitude slower. In clear urban air (low in $\mathrm{OH}$ ) the agent may ventilate before beginning to oxidize even if abstraction proceeds at the upper end rate $10^{-11} \mathrm{~cm}^{3}$ molecule $\mathrm{s}^{-1}$. The partial hydrogen hydroxyl rate constant for ethane is about $0.05 \times 10^{-12} \mathrm{~cm}^{3}$ hydrogen ${ }^{-1} \mathrm{~s}^{-1}$ at room temperature. This suggests the isopropyl group methyl may react at a total of $0.3 \times 10^{-12} \mathrm{~cm}^{3}$ molecule $\mathrm{e}^{-1} \mathrm{~s}^{-1}$, which does not alter our major conclusions here.

\section{Aerosol Reactions}

Our preliminary sarin release scenario invokes evaporation from an open container at ambient temperature. Dilution follows rapidly in the vapor phase. The agent is so highly toxic that it is still dangerous if it is breathed or otherwise ingested. The Tokyo subway attack demonstrates this vividly. However, unless temperature reductions ensue sarin is necessarily present at less than its vapor pressure. No thermodynamic driving force exists for condensation of the pure substance. Interactions remain possible with extant condensed phases of the urban aerosol. We now catalog heterogeneous processes available to the nerve agent and place limits on their rates. 
Time constants for sarin to contact particles are computed in a manner identical to that outlined above for more typical aerosol components. The agent could be depleted from the vapor into condensed phases in as little as a few seconds if rapid reactions take place. The diameter decades $0.01-0.1 \mu$ and $0.1-1 \mu$ are competitive in sustaining collisions with the trace vapor except perhaps near busy roadways during a traffic pulse. The removal time scales inversely with the surface sticking coefficient $\alpha$.

At humidities above about $50 \%$ the inorganic salts comprising the bulk of the fine-mode aerosol are expected to deliquesce (acquire liquid water). The particulate phase thus constitutes a strong aqueous ionic solution. Sarin hydrolysis reactions are relatively wellknown (Figure 5). They occur within the tissues of poisoned organisms (Shih et al., 1991) and are critical to basic military decontamination procedures (Yang et al., 1992; Yoza et al., 1997). It is often the hydrolysis products which are detected to provide evidence of sarin application (Verweij and Boter, 1975; Verweij et al., 1979 Dagostino and Provost, 1992). For example, the phosphorus acid derivatives were preserved on Kurdish soils for many months after Iraqi attacks and eventually lent support to claims that local civilians had been victimized (Ember, 1993). The hydrolyses rapidly create nontoxic products. However, they are likely to be slow at the $\mathrm{pH}$ of the urban aerosol (Ellin et at., 1981; Harris et al., 1982; Seinfeld, 1986).

Many other reaction types are possible. Gas-phase oxidants enter the aerosol and accumulate there (Jacob and Hoffman, 1983; Jacob, 1986). They seek reduced species such as organics, and the sarin side chains would be prime targets. At high-ionic strengths, nucleophiles abound. The tendency to undergo substitution in solution is a key property of cholinesterase inhibitors (Metcalf, 1982; Gearien, 1982). SN would undoubtedly transpire in aqueous particles (Lohs, 1980). Pesticides have been known to photolyze in atmospheric aqueous phases (Brown et al, 1993). Multifunctional organic oxygenates surround particles in the fine mode, behaving as surfactants (Pandis et al., 1993). Affinity for hydrophobic end groups could enhance the initial sarin sticking probability. The effect has actually been observed for parathion on fog droplets (Glotfelty et al., 1987). Schomberg et al. (1991) have speculated that pesticides are actually harbored in colloidal complexes in fog water. Heterogeneous decomposition of organic nitrates and especially PAN-like compounds may constitute a significant recycling source for $\mathrm{NO}_{\mathrm{x}}$ in cities (Ravishankara, 1997). Sarin breaks down rapidly on wetted laboratory glass surfaces (Ward et al., 1991). 
Some of these aerosol reaction channels lead to detoxification of the nerve agent; others would not. Kinetic and product information are almost entirely lacking. Since maximum rates for contacting the aerosol exceed those of net gas-phase oxidations, the heterogeneous reactions are of potential import. We classify them as a high research priority. The collective aerosol interaction possibilities are referred to along with gas-phase oxidations in Figure 10.

The fractional volume occupied by particles in an urban atmospheres is vanishingly small. An RSP mass of $100 \mu \mathrm{g} \mathrm{m}^{-3}$ translates to a water equivalent of volume of $10^{-10} \mathrm{~cm}^{3}$ (aerosol) $\mathrm{cm}^{-3}$ (air). The Henry's Law constants for organophosphorus pesticides and nerve agents are sufficiently near unity that partitioning into the aerosols is not favored. Reactions must proceed rapidly for mass transfer from the vapor phase to be significant. A small solubilized portion of highly toxic substance may nevertheless be of interest. Given the enormous uncertainties in sarin heterogeneous chemistry, entry into the aqueous phase could actually have a stabilizing effect relative to the vapor. Agent contained in particles is isolated from gaseous oxidants. Brownian approach to ground and structural surfaces is slow so that deposition velocities are reduced. If the molecule does not decompose in or on the aerosol, its lifetime may rise to on the order of weeks against deposition (Seinfeld, 1986). Most large metropolises including Los Angeles and Mexico City ventilate in one to two days. Long-range transport of sarin may be achievable toward suburban and nonurban areas.

\section{Discussion}

Through analyses of (1) the atmospheric chemistry of organophosphorus pesticides, (2) structure-reactivity relationships for atmospheric hydrocarbons, and (3) aerosol heterogeneous physicochemistry, we have established likely pathways for the degradation of sarin in urban atmospheres. Some limits have also been placed on their rates. Time constants could be as short as one hour for hydrogen abstraction by the hydroxyl radical and minutes for rapid reaction at particle surfaces.

We have stressed that our estimates for sarin loss time scales are quite uncertain. They of course depend initially on highly variable local concentrations of several types of reactant. More important, physical parameters defined in the loss mechanisms are poorly constrained. Rate constants for hydrogen atom abstraction by hydroxyl cannot be 
accurately computed because the electron withdrawing capacity of the phosphorus fluoridate group is unknown. Neither the efficiency for sticking at aerosol surfaces nor the rate of removal within particles has been measured. Laboratory experiments and improved theoretical treatments could reduce the error bars inherent in our work.

Rates for the hydrogen abstraction have been based largely on a handful of electron induction correlations (e.g., Atkinson, 1987). While our approach is comparable to the state of the art in atmospheric chemistry, more complete evaluation of the sarin structure could illuminate the role of the phosphate group in determining the electronic distribution on organic side chains. We would envision employing the sophisticated molecular modeling software now on the market. Program names include MOPAK and ALCHEMY. Reactions at the phosphorus center have not been investigated here. The inorganic chemistry database could reveal analog molecules for which gas phase reaction rate constants are known (e.g., Cotton and Wilkinson, 1972). The lack of interactions between atmospheric oxidants and the $\mathrm{P}$ atom in the pesticide species is an indication that decomposition of the methyl and isopropyl groups dominate. However, closure demands some examination of the inorganic literature. It should be noted that we have avoided mention of the temperature dependence of the gas-phase rate constants drawn upon or estimated. The assumption of constant temperature can be rationalized to some extent by the complexity of the general problem. Ultimately, however, temperature effects must be incorporated into models of sarin chemistry/transport. This means that activation energies must be deduced in addition to absolute rates.

Laboratory studies can readily be conceived which would yield values for the critical rate processes. They would be patterned after the techniques of basic atmospheric chemistry research (Finlayson Pitts and Pitts, 1986 and 1997; Ravishankara, 1997). Studies of gas phase kinetics for sarin could provide data on rate constants for hydroxyl attack and on product distributions. They would be cumbersome and expensive relative to their predecessors; exposure of the experimenter to the reactant would have to be prevented. However, it is said that the sarin used in the Tokyo incident was synthesized in a standard fume hood (TSSI, 1997). Furthermore, the syntheses involved in preparation of atmospheric chemistry experiments are often dangerous and toxic vapors are familiar. Classic heterogeneous chemistry experiments are in order. Flow tube and Knudsen cell reactors are typical equipment. The complexity of the experiments might be reduced through the analog strategy employed to investigate OP pesticide kinetics. Sarin simulants have been developed with varying degrees of realism and toxicity (Das Grupta et al., 
1988). Experiments conducted on reactive surfaces could also contribute to understanding of deposition processes for the nerve agents.

Embedded in the issue of product distributions is yet another level of uncertainty - that of the product toxicities. We have essentially restricted ourselves to the comment that cholinergic activity requires a viable leaving group (Fest and Schmidt, 1973; Metcalf, 1982). Since the products themselves are almost entirely mysterious; their potential as esterase inhibitors has not been quantified. Toxicity can of course be measured clinically (Cherniak, 1988). The experiments might be coupled to controlled laboratory sarin oxidations. Molecular modeling can also clarify cholinergic potential.

It will be remembered by the reader that we have consciously based our development solely on the open scientific literature. Indications are that the urban chemistry of nerve agents has not been investigated in detail (Lohs, 1980; Ministry for Foreign Affairs of Finland, 1985). However, we recognize that some of the studies we advocate may have been performed within the defense establishment. Our open research on sarin is justified by the immediate threat of terrorist releases, combined with the inaccessibility of any relevant classified information.

Our ultimate goal is to simulate the interactions of sarin with a city atmosphere in a threedimensional tracer transport context. The terrorist potential of the chemical and biological warfare agents (TSSI, 1997) has lately inspired the development of ultra-high resolution models of flow in the urban regime (Daisey et al., 1997). Several of us are involved in representing the atmospheric motions along buildings and streets near major targets. Resolution is approaching ten meters in our programs. A tool relied upon in such detailed flow simulations is the HIGRAD advection routine, a descendent of early positive definite transport algorithms employing reverse advection velocities to counter numerical diffusion/dispersion (Smolarkiewicz, 1983; Smolarkiewicz and Rasch, 1991). Other groups have ten meter capability as well (Hoydysh and Dabbert, 1994; Theurer et al., 1996; Daisey et al., 1997). As our sarin breakdown schemes evolve, they can be inserted as multiple tracers into the transport codes. A potential complication is that higher concentrations of the agent near-source will impact oxidant chemistry locally. The phenomenon may be discernible on the fine scale. Initial hydrogen abstraction steps are net losses of radicals in the HOx family. During decomposition of the sarin structure, hydrogen atoms are released as oxides so that back-filling takes place (Crutzen, 1988; Elliott et al., 1994 and 1996). It may be necessary to couple sarin and its byproducts into a 
full urban photochemistry mechanism. In other words, it may not be feasible to handle oxidants off-line. We plan to begin adding the nerve agent and its decay products to atmospheric chemistry schemes in low-dimensionality test runs.

The incorporation of agent chemistry into a three-dimensional street canyon scale model will constitute a valuable endeavor in and of itself; the potential for terrorism is quite real. However, we anticipate benefits to urban air quality models as well. Air pollution problems have most often been simulated over entire cities and at kilometer resolution or coarser (e.g. McRae et al., 1982). Localized pollution problems can be subgrid in scale, and nonlinearities associated with near-source levels of specific compounds are smeared through averaging. Our programs should be adaptable to the study of air quality at the street corner level.

\section{Summary}

Terrorism employing chemical and biological weapons is fast becoming a reality in major metropolitan areas around the world (Department of Commerce, 1994; Ember, 1995; TSSI, 1997). Attacks typically involve dissemination of an agent though the urban atmosphere so that photochemical and phase transformation are possibilities in some cases. Products of the changes may still be toxic and persistent. As an example of the complexity which will be attained during agent oxidations and of the degree to which details can be understood from first principles, we have performed an investigation of atmospheric chemistry for the nerve gas sarin. The molecule has seen documented military applications in recent years (Ember, 1993; McCarthy, 1997). It has been deployed in a major urban zone in peacetime, and that has caused massive casualties (Okumura et al., 1996; Yokoyama et al., 1996). The chemical structure of sarin happens to be reasonably simple (Verweij et al., 1979) and is similar to a class of pesticides for which rates of atmospheric transformations have been measured.(Winer and Atkinson, 1990). We set as objectives the definition of pathways for sarin decay in urban air and the estimation of uncertainties in their rates. Initial emphasis is placed on information available in the open literature, since time may be of the essence in analyzing terrorist situations. Followups are planned in the context of defense sources.

Our work begins with a review of the development and uses of nerve agents over the decades (Hoeber and Douglass, 1978; Dunn and Sidell, 1989). As background, the mechanism of cholinesterase inhibitions is sketched for the nervous systems of higher animals (Metcalf, 1982). The recent urban sarin incident in Tokyo is then described in full 
(Ember, 1995). It is noted that the Tokyo release mechanism was exceedingly rudimentary. Liquid agent was left to evaporate from open paper bags (TSSI, 1997). Most of the several thousand injuries were caused by sarin dispersed through the vapor perase (Ohbu et al., 1997). A study scenario is designed based on the Japanese incident which allows for chemical and phase changes to take place. It consists of outdoor injection into a city atmosphere in the morning, during the period of decreasing stability of the nocturnal boundary layer and increasing photolytic activity. Sarin is assumed to begin its transport as a gas, to react with major oxidant species, and to interact with pollutant particles. With a generic case at hand for study, we move on to the identification of channels and calculation of rates.

As a first step in elucidating the sarin atmospheric chemistry, we outline current knowledge of the transformations of the analog organophosphorus pesticides (Lewis and Lee, 1976). They have been closely scrutinized as hazardous pollutants subject to long-range transport, particularly in California's Central Valley and Sierra Nevada mountains (Glotfelty et al., 1990; Aston and Seiber, 1996). The OP insect control species differ from the nerve agents in that they are released into the atmosphere in the thion ester form (Glotfelty et al., 1987). The more toxic oxon is meant to arise only in the guts of the target organisms (Metcalf, 1982). However, oxidation of the thion can occur incidentally in transit. It is the family of oxon phosphorus esters which is most dangerous (Seiber et al., 1989). Their atmospheric degradation has been quantified empirically and it occurs in on the order of hours to days depending on local conditions and on molecular structure (Woodrow et al., 1983). Overall breakdown mechanisms are not known, but initiation has been studied for model compounds such as trimethyl phosphate (Winer and Atkinson, 1990). Rate constants for hydrogen abstraction by the hydroxyl radical are consistent with the field studies. Direct photolysis and reaction with ozone appear to be slow. A footnote of some interest is that many known pesticide decay sequences lead to intermediates with toxicities equal to or greater than those of parent species (Seiber and Woodrow, 1994).

At this point in our investigation we pinpointed the major reactants accessible to organic vapors in the urban environment (Finlayson Pitts and Pitts, 1997). The pesticide research suggests that hydroxyl, ozone, and ultraviolet/visible photons should all be assessed. To this list we add the variety of urban aerosols. Concentration ranges are set for the city reactants through a sampling of results which have been obtained in two of the world's most populous and polluted areas, the Los Angeles basin and Valley of Mexico. We selected these as baseline locations because they are representative of domestic and 
developing megacities, respectively, and because we have participated in the evaluation of their vexing but distinct pollution problems (MARI, 1994; Elliott et al., 1997a and 1997b). Nonlinearities in the organic/oxidant/ozone system are outlined (Blake and Rowland, 1995). The aerosol is treated as a set of ammonium nitrate and sulfate equilibria (Russell et al., 1983) with low volatility organics superimposed (Pandis et al., 1993). The culmination is a table of upper and lower concentration limits for the specified reactants at midday.

The heart of our sarin work consists of structure-reactivity estimates for the rate of hydroxyl radical attack upon attached hydrogen atoms. We argue that the ozone and photolysis reactions will be less important. The trimethyl phosphate rate constants (Winer and Atkinson, 1990) are cast into activation enthalphy correlations with more familiar atmospheric organics such as alkanes and hydrocarbon oxygenates (Atkinson, 1987; Gaffney et al., 1986). Classical free energy relationships are called upon for guidance, including the Hammett theory for benzoic acid derivatives and inductive effects in halogenated straight chain alkanoic acids (Fieser and Fieser 1961). The phosphorus ester linkage seems to behave through induction as a mild electron donor relative to the proton. It resembles carbon esters and alcohol substituents in this regard. One thus expects abstraction of at least some hydrogens from the sarin alkyl group at $10^{-12} \mathrm{~cm}^{3}$ molecule ${ }^{-1} \mathrm{~s}^{-1}$ (Winer and Atkinson, 1990). On the other hand, strong electron withdrawal by the fluoridate will countermand the activation. The degree of the counter-effect is difficult to quantify. We therefore set the abstraction rate constant at $10^{-12}$ to $10^{-11}$ as a fast limit for an initial oxidation step. The sarin lifetime varies from as little as hours upward to many days given the uncertainties and the range of hydroxyl concentrations set for the urban atmosphere. The molecule is photochemically stable under the morning inversion in our standard scenario and begins to degrade as solar angles change.

Products resulting from hydrogen abstraction cannot be predicted. The proton interior to the isopropyl grouping is likely to be removed first because its neighboring methyl groups serve as electron donors. The radical which remains could fall apart through well-known atmospheric oxidation steps to a small oxygenate such as acetone and a sarin hydrolysis derivative. The acids that are produced through nerve agent hydrolysis are not toxic (Verweij et al., 1979). However, methyl hydrogens are numerous on the sarin skeleton and their loss could be important channels for statistical reasons (Gaffney et al., 1986). Oxidation of the methyls would lead by analogy with simple alkanes to aldehyde or nitrate moieties. Their structures are sufficiently similar to that of sarin to retain high toxicity. The critical factor is preservation of the fluorine-leaving group which permits esterification of 
the choline enzyme. Some perspective on the toxicity issue is provided by the medical and pesticide literatures, which consider biological effects as functions of small structural disparities (O'Brien, 1960; Vojvodic, 1973; Boskovic and Kusic, 1980; SIPRI, 1980).

Other gas-phase oxidation pathways and product lines can only be speculated upon. The hydroxyl radical could conceivably attack the phosphorus atom. A methyl radical might be displaced. The phosphorus-to-fluorine bond is a weak one subject to breakage (Cotton and Wilkinson, 1972). An addition to examining vapor-phase oxidation, we have computed rates for sarin transfer to the surface of the aerosol. The time scales are potentially faster than the hydrogen abstraction range. Urban particles are strong aqueous ionic solutions at relative humidity above about $50 \%$. Hydrolyses and nucleophilic substitutions may deactivate sarin in the liquid phase (Verweij et al., 1979). Oxidation and photolysis reactions are possibilities as well (Brown, 1993), with unknown product distributions. Organic coatings (Pandis et al., 1993) complicate but may possibly expedite the entry of the nerve agent into aqueous particulates. Rates for aerosol uptake have not been measured. The fine mode of the urban size spectrum sediments only slowly and so could serve as a vehicle for long-range transport. We excluded fog interactions and wet deposition in rain from the present analysis.

A closing discussion distills some of the uncertainties in our manipulations and indicates avenues for further investigation. We have based our current characterization of vapor phase sarin loss pathways on a few energy correlations from rather early atmospheric research (Gaffney et al., 1986; Winer and Atkinson, 1990). Error bars might be narrowed through the application of more sophisticated energetic analyses. For example, desktop molecular modeling software now gives the individual chemist the ability to visualize electron densities for arbitrary compounds. Density maps could shed light on induction along the sarin backbone. It might also prove profitable to search inorganic as opposed to atmospheric chemical databases for rate information. Other means for reducing uncertainties are itemized as well. We performed our calculations solely for roomtemperature energetics. Activation and enthalpy effects must be factored in. Laboratory experiments can be envisioned for the determination of nerve agent reaction rates and product distributions. They would resemble traditional work in atmospheric kinetics (Finlayson Pitts and Pitts, 1997) but would be more dangerous and expensive (Zapf, 1993). Product toxicities may be determined clinically (Tripathi et al., 1989), or through further molecular modeling, of the outstanding cholinergic microsymptoms (Politzer and Jayasuriya, 1986). Although particle contact rates are easily computed, rapid reactions in 
the aerosol are required to support mass transfer. Data on surface interactions are wholly lacking. Boundary processes such as adsorption and deposition have been largely ignored here as a means of achieving tractability. In the urban environment, surfaces and surface chemistry will-be varied and must be accounted for (Crump and Seinfeld, 1981; Baldocchi et al., 1987; Taylor and Spencer, 1990; Taylor and Constable, 1994). Finally, we reiterate that we have not yet begun to exploit research by the defense establishment.

The discussion section also touches upon some ramifications of our findings. With hoaxes and real chemical/biological terrorist attacks now coming at regular intervals in world cities (TSSI, 1997), the atmospheric sciences community is mobilizing to produce incident models. Both indoor and outdoor computational fluid dynamics coding will be adopted (Daisey et al., 1997). Some groups are capable of simulating transport in the complex urban arena of building surfaces and street canyons to ten meter resolution or finer (Theurer et al., 1996; Daisey et al., 1997). Accurate portrayal of the dispersion of the nerve agents and their decomposition products will require complete decay schemes and a knowledge of the embedded uncertainties. It is even possible that the chemistry of sarin degradation will have to be coupled to that of city air, since high local organic concentrations could alter oxidant fields and so lead to nonlinearities. Our estimates here assume that sarin oxidation proceeds independently. Insights from such detailed studies of chemistry transpiring in urban air may ultimately hold benefits for general pollution research. Early steps for the incorporation of full agent physicochemistry into microscale models may include lowdimensionality demonstrations. 


\section{References}

Aldape, F., Flores, M.J., Diaz, R.V., and Crumpton, D., Temporal variations in elemental concentrations of atmospheric aerosols in Mexico City, Nucl. Instrum. Methods Phys.

Res. 75 (B), 304-307 (1993).

Aldape, F., Flores, M.J., Diaz, R.V., Miranda, J., Cahill, T.A., and Morales, J.R., Two year study of elemental composition of atmospheric aerosols in Mexico City, Int. J. PIXE 1, 373-388 (1991b).

Aldape, F., Flores, M.J., Diaz, R.V., Morales, J.R., Cahill, T.A., and Saravia, L., Seasonal study of the composition of atmospheric aerosols in Mexico City, Int. J. PIXE 1, 355-371 (1991a).

Aston, L.S. and Seiber, J.N., Methods for the comparative analysis of organophosphate residues in four compartments of needles of Pinus ponderosa, J. Agric. Food Chem 44, 2728-2735 (1996).

Atherton, C.S. and Penner, J.E., The effect of biogenic hydrocarbons on the transformation of nitrogen oxides in the troposphere, J. Geophys. Res. 95, 14027-14038 (1990).

Atherton, C.S. and Penner, J.E., The transformation of nitrogen oxides in the polluted troposphere, Tellus B 40, 380-392 (1988).

Atkinson, R., Estimation of gas-phase hydroxyl radical rate constants for organic chemicals, Environ. Toxicol. Chem. 7, 435-442 (1988).

Atkinson, R., Kinetics and mechanisms of the gas phase reactions of the hydroxyl radical with organic compounds under atmospheric conditions, Chem. Rev. 86, 69-201 (1986).

Atkinson, R., A structure-activity relationship for the estimation of rate constants for the gas-phase reactions of $\mathrm{OH}$ radicals with organic compounds, Int. J. Chem. Kinet. 19, 799-828 (1987).

Atkinson, R., Aschmann, S.M., Arey, J., McElroy, P.A., and Winer, A.M., Product formation from the gas-phase reactions of the $\mathrm{OH}$ radical with $\left(\mathrm{CH}_{3} \mathrm{O}\right)_{3} \mathrm{PS}$ and $\left(\mathrm{CH}_{3} \mathrm{O}\right)_{2} \mathrm{P}(\mathrm{S}) \mathrm{SCH}_{3}$, Environ. Sci. Technol. 23, 243-244 (1989).

Atkinson R. and Carter, W.P.L., Kinetics and mechanisms of the gas-phase reactions of ozone with organic compounds under atmospheric conditions, Chem. Rev. 84, 437-470 (1984).

Atkinson, R. and Lloyd, A.C., Evaluation of kinetic and mechanistic data for modeling of photochemical smog, J. Phys. Chem. Ref. Data 13 (2), 315-439 (1981).

Baldocchi, D.D., Hicks, B.B., and Camara, P., A canopy stomatal resistance model for gaseous deposition to vegetated surfaces, Atmos. Environ. 21 (1), 91-101 (1987).

Barden, J.D. et al., Remote sensing technology and CW arms control, P650-1254G-1, 7, Kaman Sciences Corp., Alexandria, VA. (Feb 2, 1993).

Bassett, M. and Seinfeld, J.H., Atmospheric equilibrium model of sulfate and nitrate aerosols, Atmos. Environ. 17, 2237 (1983). 
Bassett, M. and Seinfeld, J.H., Atmospheric equilibrium model of sulfate and nitrate aerosols - II. Particle size analysis, Atmos. Environ. 18, 1163 (1984).

Blake, D.R. and Rowland, F.S., Continuing worldwide increase in tropospheric methane, 1978-1987, Science 239, 1129-1131 (1988).

Blake, D.R. and Rowland, F.S., Global concentrations and source strength of ethane, Nature 321, 231-233 (1986).

Blake, D.R. and Rowland, F.S., Urban leakage of liquefied petroleum gas and its impact on Mexico City air quality, Science 269, 953-956 (1995).

Boskovic, B. and Kusic, R., Long-term effects of acute exposure to nerve gases upon human health. In Chemical Weapons: Destruction and Conversion, p. 113, Stockholm International Peace Research Institute, Taylor \& Francis Ltd., London (1980).

Brown, M.A., Petreas, M.X., Okamoto, H.S., Mischke, T.M., and Stephens, R.D., Monitoring of malathion and its impurities and environmental transformation products on surfaces and in air following an aerial application, Environ. Sci. Technol. 27, 388-397 (1993).

Canada, Verification methods, handling, and assessment of unusual events in relation to allegations of the use of novel chemical warfare agents, Government of Canada, Ottawa (March 1990).

Cherniak, M.G., Toxicological screening for organophosphorus-induced delayed neurotoxicity: complications in toxicity testing, Neurotoxicology 9, 249-272 (1988).

Coats, J.R., Pesticide degradation mechanisms and environmental activation, ACS Symposium Series 459, Ch. 2, 200th National Meeting, Washington, DC (1990).

Cohen, N., The use of transition-state theory to extrapolate rate coefficients for reactions of OH with alkanes, Int. J. Chem. Kinet. 14, 1339 (1982).

Cory, L., Fjeld, P., Serat, W., Distribution patterns of DDT residues in the Sierra Nevada Mountains, Pesticides Monitoring Journal 3, 204-211 (1970).

Cotton, F.A. and Wilkinson, G., Advanced Inorganic Chemistry (3rd Ed.), Interscience Publishers, New York (1972).

Crump, J.G. and Seinfeld, J.H., Turbulent deposition and gravitational sedimentation of an aerosol in a vessel of arbitrary shape, J. Aerosol Sci. 12 (5), 405-415 (1981).

Crutzen, P.J., A discussion of the chemistry of some minor constituents in the stratosphere and troposophere, Pure Appl. Geophys. 106, 1385-1399 (1973).

Crutzen, P.J., Tropospheric ozone: an overview. In Tropospheric Ozone (Edited by I.S.A. Isaksen), pp. 3-32, D. Reidel, Dordrecht (1988).

Dagostino, P.A., and Provost, L.R., Determination of chemical warfare agents, their hydrolysis products and related compounds in soil, J. Chromatography 589 (1-2), 287-294, 1992. 
Daisey, J.M., Ermak, D.L., Policastro, A.J., Streit, G.E., et al., Study and discussion of models applicable to the transport and fate thrust area of the Department of Energy chemical and biological nonproliferation program, LA-CP-166, Los Alamos National Laboratory, Los Alamos, New Mexico (1997).

Darnall, K.R., Carter, W.P.L., Winer, A.M., Lloyd, A.C., and Pitts, J.N. Jr., Importance of $\mathrm{RO}_{2}+\mathrm{NO}$ in alkyl nitrate formation from $\mathrm{C}_{4}-\mathrm{C}_{6}$ alkane photooxidations under simulated atmospheric conditions, J. Phys. Chem. 80, 1948 (1976).

Das Gupta, S., Deshpande, S.B., and Warnick, J.E., Segmental synaptic depression caused by diisopropylphosphorofluoridate and sarin is reversed by thyrotropin-releasing hormone in the neonatal rat spinal cord, Toxicology and Applied Pharmacology 95, 499506 (1988).

Davis, D.D., Bollinger, W., and Fischer, S., A kinetics study of the reaction of the $\mathrm{OH}$ free radical with aromatic compounds, I. Absolute rate constants for reaction with benzene and toluene at $300^{\circ} \mathrm{K}$, J. Phys. Chem. 79, 293 (1975).

Demore, W.B., Sander, S.P., Golden, D.M., Molina, M.J., Hampson, R.F., Kurylo, M.J., Howard, C.J., and Ravishankara, A.R., Chemical kinetics and photochemical data for use in stratospheric modeling, evaluation number 9, Jet Propulsion Laboratory Publ. 90-1 (1990).

Department of Commerce, Technologies underlying weapons of mass destruction (1994).

De Voogt, P. and Jansson, B., Vertical and long-range transport of persistent organics in the atmosphere, Rev. Environ. Contamination \& Toxicology, 132, 127 (1993).

Dodge, M.C., Combined use of modeling techniques and smog chamber data to derive ozone-precursor relationships, Proceedings of the International Conference on

Photochemical Oxidant Pollution and Its Control, II, Dimitriades, EPA-600/3-77-001b, 881-889 (1977).

Dunn, M.A. and Sidell, F.R., Progress in medical defense against nerve agents, J. Amer. Med. Assn. 262 (5), 649 (Aug. 4, 1989).

Ellin, R.I., Groff, W.A., and Kaminskis, A., The stability of sarin and soman in dilute aqueoussolutions and the catalytic effect of acetate ion, J. Environ. Science and Health, Part B - Pesticides, food contaminants, and agricultural wastes 16 (6), 713-717 (1981)

Elliott, S., Blake, D.R., Rowland, F.S., Lu, R., Brown, M., Willaims, M., Russell, A.G., Bossert, J.E., Streit, G., Proch, W., Ruiz Santoyo, M., Guzman, F., McNair, L.A., Kao, C.Y.J., Turco, R.P., and Eichinger, W., Ventilation of liquefied petroleum gas components from the valley of Mexico, J. Geophys. Res. 102 (D17), 21 197-21207 (1997a).

Elliott, S., Cicerone, R.J., Turco, R.P., Drdla, K., and Tabazadeh, A., Influence of the heterogeneous reaction $\mathrm{HCl}+\mathrm{HOCl}$ on an ozone hole model with hydrocarbon additions, J. Geophys. Res. 99 D2, 3497-3508 (Feb. 20, 1994).

Elliott, S., Kao, C.Y.J., Shen, M., Turco, R.P., and Jacobson, M.Z., A streamlined family photochemistry package reproduces major nonlinearities in the tropospheric ozone system, Computers and Chemistry 20 (2), 235-259 (1996). 
Elliott, S., McNair, L.A., Williams, M., Russell, A.G., Blake, D.R., Rowland, F.S., Streit, G.E., Brown, M.J., Lu, R., Keyantash, J., Turco, R.P., Ruiz Santoyo, M., Guzman, F., Bossert, J.E., and Gupta, M., Valley of Mexico propane distributions simulated in an urban grid system. In Environ. Modeling (Edited by P. Zannetti), Chap. 4. Computational Mechanics Publications, Southampton United Kingdom (1997b).

Ember, L., Chemical weapons: residues verify Iraqi use on Kurds, Chem. \& Environ. News, 8-10 (May 3, 1993).

Ember, L., Details emerge of sarin attack by cult in Tokyo, Chem. \& Eng. News 73 (24), 2 (1995).

Falls, A.H. and Seinfeld, J.H., Continued development of a kinetic mechanism for photochemical smog, Environ. Sci. Technol. 12 (13), 1398-1406 (1978).

Fest, C. and Schmidt, K.J., The Chemistry of Organophosphorus Pesticides, SpringerVerlag, New York (1973).

Fieser, L.F. and Fieser, M., Advanced Organic Chemistry, Ch. 16-26, Van Nostrand Reinhold Co., New York (1961).

Finlayson Pitts, B.J. and Pitts, J.N. Jr., Atmospheric Chemistry: Fundamentals and Experimental Techniques, Wiley-Interscience, New York (1986).

Finlayson Pitts, B.J. and Pitts, J.N. Jr., Tropospheric air pollution: ozone, airborne toxics, polycyclic aromatic hydrocarbons, and particles, Science 276, 1045 (May 16, 1997).

Foye, W.O., Principles of Medicinal Chemistry, pp. 322-323, Lea and Febiger, Philadelphia, Pa. (1975).

Friedlander, S.K., Smoke, Dust, and Haze: Fundamentals of Aerosol Behavior, WileyInterscience, New York (1977).

Fuchs, N.A., The Mechanics of Aerosols, Pergamon Press, Oxford (1964).

Gaffney, J.S., Fajer, R., Senum, G.I., and Lee, J.H., Measurement of the reactivity of $\mathrm{OH}$ with methyl nitrate: implications for prediction of alkyl nitrate-OH reaction rates, Int. $J$. of Chem. Kinetics 18, 399-407 (1986).

Gaffney, J.S. and Levine, S.Z., Predicting gas phase organic molecule reaction rates using linear free-energy correlations, I. $\mathrm{O}\left({ }^{3} \mathrm{P}\right)$ and $\mathrm{OH}$ addition and abstraction reactions, Int. J. of Chem. Kinetics XI, 1197-1209 (1979).

Gearien, J.E., Cholinesterase inhibitors. In Encyclopedia of Chemical Technology (3rd Ed.) 6, pp. 28-35, John Wiley \& Sons, New York (1982).

Glotfelty, D.E., Schomburg, C.J., McChesney, M.M., Sagebiel, J.C., and Seiber, J.N., Studies of the distribution, drift, and volatilization of diazinon resulting from spray application to a dormant peach orchard, Chemosphere 21 (10-11), 1303-1314 (1990).

Glotfelty, D.E., Seiber, J.N., and Liljedahl, L.A., Pesticides in fog, Nature 325, 602 (Feb. 12, 1987). 
Grosjean, D. and Friedlander, S.K., Formation of organic aerosols from cyclic olefins and diolefins, Adv. Environ. Sci. Technol. 10, 435 (1980).

Grosjean, D. and Friedlander, S.K., Gas-particle distribution factors for organic and other pollutants in the Los Angeles atmosphere, J. Air Pollut. Control Assoc. 25, 1038 (1975).

Grosjean, D., Van Cauwenberghe, K., Schmid, J.P., Kelley, P.E., and Pitts, J.N. Jr., Identification of $\mathrm{C}_{3}-\mathrm{C}_{1} \mathrm{O}$ aliphatic dicarboxylic acids in airborne particulate matter, Environ. Sci. Technol. 12, 313 (1978).

Gu, C., Rynard, C.M., Hendry, D.G., and Mill, T., Hydroxyl radical oxidation of isoprene, Environ. Sci. Technol. 19, 151 (1985).

Gunderson, C.H. Lehmann, C.R. Sidell, F.R., and Jabbari, B., Nerve agents: a review, Neurology 42 (5), 946-950 (1992).

Gusten, $\mathrm{H}$., Correlation of hydroxyl radical abstraction rate constants with electron capture cross sections, J. of Atmos. Chem. 2, 83-92 (1984).

Hansen, D.A., Atkinson, R., and Pitts, J.N. Jr., Rate constants for the reaction of OH radicals with a series of aromatic hydrocarbons, J. Phys. Chem. 79, 1763 (1975).

Hard, T.M., O'Brien, R.J., Chan, C.Y., and Mehrabzadeh, A.A., Tropospheric free radical determination by FAGE, Environ. Sci. Technol. 18, 768 (1984).

Harris, B.L., Shanty, F., and Wiseman, W.J., Chemicals in war. In Encyclopedia of Chemical Technology (3rd Ed.) 5, pp. 393-416, John Wiley \& Sons, New York (1982).

Herdan, G., Small Particle Statistics (2nd Edn), Academic Press, New York (1960).

Heicklen, J., The correlation of rate coefficients for $\mathrm{H}$-atom abstraction by $\mathrm{HO}$ radicals with C-H bond dissociation enthalpies, Int. J. Chem. Kinet. 13, 651 (1981).

Hidy, G.M., Summary of the California aerosol characterization experiment, J. Air Pollution Control Assoc. 25, 1106-1114 (1975).

Hoeber, A.M. and Douglass, J.D., The neglected threat of chemical warfare, International Security, 55-82 (1978).

Hoydysh, W.G. and Dabberdt, W.F., Concentration fields at urban intersections: fluid modeling studies, Atmos. Environ. 28 (11), 1849-1860 (1994).

Ho, W.W., Hidy, G.M., and Govan, R.M., Microwave measurements of the liquid water content of atmospheric aerosols, J. Appl. Meteorol. 13, 871 (1974).

Hov, O., Schjoldager, J., and Wathne, B.M., Measurement and modeling of the concentrations of terpenes in coniferous forest air, J. Geophys. Res. 88 (C15), 10,679$10,688(12 / 20 / 83)$.

Hubler, G., Perner, D., Platt, U., Toennissen, A., and Ehhalt, D.H., Ground level OH radical concentration: new measurements by optical absorption, J. Geophys. Res. 89, 1309 (1984).

Ishikawa, S., Noncholinergic toxicity of sarin, Internal Medicine 36 (7), 447 (1997). 
Jacob, D.J., Chemistry of $\mathrm{OH}$ in remote clouds and its role in the production of formic acid and peroxy monosulfate, J. Geophys. Res. 91, 9807-9826 (1986).

Jacob, D.J. and Hoffman, M.R., A dynamic model for the production of $\mathrm{H}^{+}, \mathrm{NO}_{3}^{-}$, and $\mathrm{SO}_{4}^{-2}$ in urban fog, J. Geophys. Res. 88C, 6611 (1983).

Jacob, D.J., Sillman, S., Logan, J.A., and Wofsy, S.C., Least independent variables method for simulating tropospheric ozone, J. Geophys. Res. 94, 8497-8510.

Jamal, G.A., Long-term neurotoxic effects of chemical warfare organophosphate compounds (sarins), Adverse Drug Reactions and Toxicological Reviews 14 (2), 83-84 (1995).

Kato, T. and Hamanaka, T., Ocular signs and symptoms caused by exposure to sarin gas, Amer. J. Ophthalmology 121 (2), 209-210 (1996).

Kittelson, D.B. and Dolan, D.F., Diesel exhaust aerosols. In Generation of Aerosols and Facilities for Exposure Experiments (Edited by K. Willeke), pp. 337-359. Ann Arbor Science, Ann Arbor, MI (1980).

Klisenko, M.A. and Pis'mennaya, M.V., Photochemical conversion of organophosphorus pesticides in air, Gig. Tr. Prof. Zabol, 56 (1979).

Kurata, H., Lessons learned from the destruction of the chemical weapons of the Japanese Imperial Forces. In Chemical Weapons: Destruction and Conversion, p. 77, Stockholm International Peace Research Institute, Taylor \& Francis Ltd., London (1980).

Kutz, F.W. et al., National surveillance program for pesticides in air. In Air Pollution from Pesticides and Agricultural Processes (Edited by Robert E. Lee, Jr., EPA), Chap. 4, pp. 95-135. CRC Press, Cleveland, OH (1976).

Lawrence Berkeley Laboratory, Instrumentation for Environmental Monitoring Air I (2). LBL, Livermore, CA (Sept. 2, 1979).

Lewis, R.G. and Lee, R.E. Jr., Air pollution from pesticides: sources, occurrence, and dispersion. In Air Pollution from Pesticides and Agricultural Processes (Edited by Robert E. Lee, Jr., EPA), pp. 5-50. CRC Press, Cleveland, OH (1976).

Lin, X., Trainer, M., and Liu, S.C., On the nonlinearity of the tropospheric ozone production. J. Geophys. Res. 93, 15,879-15,888 (1988).

Little, J.S., Broomfield, C.A., Foxtalbot, M.K., Boucher, L.J., MacIver, B., and Lenz, D.E., Partial characterization of an enzyme that hydrolyzes sarin, soman, tabun, and diisopropyl- phosphorofluoridate (DFP), Biochemical Pharmacology 38 (1), 23-29 (1989).

Little, P.J., Scimeca, J.A., and Martin, B.R., Distribution of [H-3]

diisopropylfluorophosphate, [h-3] soman, [h-3] sarin, and their metabolites in mouse brains, Drug Metabolism and Disposition 16 (4), 515-520 (1988). 
Liu, S.C., Trainer, M., Fehsenfeld, F.C., Parrish, D.D., Williams, E.J., Fahey, D.W., Hubler, G., and Murphy, P.C., Ozone production in the rural troposphere and the implications for regional and global ozone distributions, J. Geophys. Res. 92, 4191-4207 (1987).

'Liu, S.C., Trainer, M., and Carroll, M., A study of the photochemistry and ozone budget during the Mauna Loa Observatory Photochemistry Experiment, J. Geophys. Res. 97, 10,463-10,470 (1992).

Lloyd, A.C., Atkinson, R., Lurmann, F.W., and Nitta, B., Modeling potential ozone impacts from natural hydrocarbons - I. Development and testing of a chemical mechanism for the $\mathrm{No}_{\mathrm{x}}$-air photooxications of isoprene and $\alpha$-pinene under ambient conditions, Atmos. Environ. 17, 1931 (1983).

Lohs, K., Destruction or conversion of chemical warfare agents: possibilities and alternatives. In Chemical Weapons: Destruction and Conversion, p. 67, Stockholm International Peace Research Institute, Taylor \& Francis Ltd., London (1980).

Lundin, S.J., The inhibition of cholinesterase activity by organophosphorus compounds as a means in an inspection procedure. In The Problem of Chemical and Biological Warfare VI, Technical Aspects of Early Warning and Verification, p. 177, Stockholm International Peace Research Institute, Almqvist \& Wiksell Int'l., Stockholm (1976).

Lundin, S.J., Properties of a cholinesterase from body muscles of plaice (Pleuronectes . platessa), Acta Chemica Scandinavica 22, 2183 (1968).

MARI, The Mexico City air quality research initiative, LA-12699, Los Alamos National Laboratory, Los Alamos, NM (1994).

Marshall, E., Too radical for NIH? Try DARPA, Science 275, 744 (Feb. 7, 1997).

Mayrsohn, H., Kuramoto, M., Crabtree, J.H., Sothern, R.D., and Mano, S.H., Atmospheric hydrocarbon concentrations, June-September 1974, State of California Air Resour. Board, Sacramento (April 1975).

Majewski, M.S., Glotfelty, D.E., and Seiber, J.N., A comparison of the aerodynamic and the theoretical-profile-shape methods for measuring pesticide evaporation from soil, Atmos. Environ. 23 (5), 929-938 (1989).

McCarthy, M., Gulf-war soldiers possibly exposed to sarin, Lancet 350 (9074), 346 (1997).

McRae, G.J., Goodin, W.R., and Seinfeld, J.H., Development of a second generation mathematical model for urban air pollution - I. Model formulation, Atmos. Environ. 16, 679-696 (1982).

Metcalf, R.L., Insect control technology. In Encyclopedia of Chemical Technology (3rd Edn) 13, pp. 413-485, John Wiley \& Sons, New York (1982).

Mikulak, R., Destruction of US chemical weapons production and filling facilities. In Chemical Weapons: Destruction and Conversion, p. 57, Stockholm International Peace Research Institute, Taylor \& Francis Ltd., London (1980). 
Ministry for Foreign Affairs of Finland, Development and evaluation of basic techniques, Part I. In Air Monitoring as a Means for Verification of Chemical Disarmament, Chap. 2. MFAF, Helsinki (1985).

Miranda, J., Morales, J.R., Cahill, T.A., Aldape, F., and Flores, J., A study of elemental contents in atmospheric aerosols in Mexico City, Atmosfera 5, 95-108 (1992).

Miranda, J., Morales, J.R., Cahill, T.A., Aldape, F., Flores, J., and Diaz, R.V., Determination of elemental concentrations in atmospheric aerosols in Mexico City using proton induced X-ray emission, proton elastic scattering, and laser absorption, Atmos. Environ. 28, 2299-2306 (1994).

Nagao, M., Takatori, T., Matsuda, Y., Nakajima, M., Iwase, H., and Iwadate, K., Definitive evidence for the acute sarin poisoning diagnosis in the Tokyo subway, Toxicology and Applied Pharmacology 144 (1), 198-203 (1997).

Nash, R.G. and Beall, M.L. Jr., A microagroecosystem to monitor the environmental fate of pesticides, Proceedings of Terrestrial Microcosms and Environmental Chemistry Syposium, pp. 86-94. Oregon State U., Corvallis, Oregon (1977).

Niki, H., Maker, P.D., Savage, C.M., and Breitenbach, L.P., Atmospheric ozone-olefin reactions, Environ. Sci. Technol. 17, 312A (1983).

Nohara, M. and Segawa, K., Ocular symptoms due to organophosphorus gas (sarin) poisoning in Matsumoto, British J. Ophthalmology 80 (11), 1023 (1996).

Nozaki, H., Aikawa, N., Fujishima, S., Suzuki, M., Shinozawa, Y., Hori, S., and Nogawa, S., A case of VX poisoning and the difference from sarin, Lancet 346 (8976), 698-699 (1995).

O’Brien, R.D., Toxic Phosphorus Esters. Academic Press, Inc., New York (1960).

Odum, J.R., Jungkamp, T.P.W., Griffin, R.J., Flagan, R.C., and Seinfeld, J.H., The atmospheric aerosol-forming potential of whole gasoline vapor, Science 276, 96 (April 4, 1997).

Ohbu, S., Yamashina, A., Takasu, N., Yamaguchi, T., Murai, T., Nakano, K., Matsui, Y., Mikami, R., Sakurai, K., and Hinohara, S., Sarin poisoning on Tokyo subway, Southern Med. Journal 144 (1), 198-203 (1997).

Ohki, T., Suzuki, M., and Aikawa, N., Secondary exposure of medical staff to sarin vapor in the emergency room, Intensive Care Medicine 21 (12), 1032-1035 (1995).

Okumura, T., Takasu, N., Ishimatsu, S., Miyanoki, S., Mitsuhashi, A., Kumada, K., Tanaka, K., and Hinohara, S., Report on 640 victims of the Tokyo subway sarin attack, Annals of Emergency Medicine 28 (2), 129-135 (1996).

Pandis, S.N., Harley, R.A., Cass, G.R., and Seinfeld, J.H., Secondary organic aerosol formation and transport, Atmos. Environ. 26A (13), 2269-2282 (1992).

Pandis, S.N., Wexler, A.S., and Seinfeld, J.H., Secondary organic aerosol formation and transport - II. Predicting the ambient secondary organic aerosol size distribution, Atmos. Environ. 27A (15), 2403-2416 (1993). 
Pandis, S.N., Wexler, A.S., and Seinfeld, J.H., Dynamics of tropospheric aerosols, J. Phys. Chem. 99 (24), 9646-9659 (1995).

Paulson, S.E. and Seinfeld, J.H., Development and evaluation of a photooxidation mechanism for isoprene, J. Geophys. Res. 97, 20,703-20,715 (1992).

Penner, J.E., Atherton, C.S., Dignon, J., Ghan, S.J., and Walton, J.J., Tropospheric nitrogen: a three-dimensional study of sources, distributions, and deposition, J. Geophys. Res. 96, 959-990 (1991).

Pickering, K.E., Thompson, A.M., Scala, J.R., Tao, W.K., Dickerson, R.R., Simpson, J., and Garstang, M., Photochemical ozone production in tropical squall line convection during NASA global tropospheric experiment/Amazon boundary layer experiment $2 \mathrm{~A}, J$. Geophys. Res. 96, 3099-3114 (1991).

Pickering, K.E., Thompson, A.M., Tao, W.K., and Kucsera, T.L., Upper tropospheric ozone production following mesoscale convection during STEP/EMEX, J. Geophys. Res. 98, 8737-8749 (1993).

Politzer, P. and Jayasuriya, K., A computational analysis and comparison of some sarin and soman analogues, Theochem 27 (3-4), 381-388 (Jan. 1986).

Ravishankara, A.R., Heterogeneous and multiphase chemistry in the troposphere, Science 276, 1058 (May 16, 1997).

Rengstorff, R.H., Accidental exposure to sarin: vision effects, Archives of Toxicology 56 (3), 201-203 (1985).

Roberts, J.D. and Caserio, M.C., Basic Principles of Organic Chemistry (2nd Edn). W.A. Benjamin, Inc., Menlo Park, CA (1977).

Robinson, J.P., Chemical warfare capabilities of the Warsaw and North Atlantic Treaty Organizations: an overview from open sources. In Chemical Weapons: Destruction and Conversion II, p. 9, Stockholm International Peace Research Institute, Taylor \& Francis Ltd., London (1980).

Robinson, J.P., The supply-side control of the spread of chemical weapons. In Limiting the Proliferation of Weapons, The Role of Supply-Side Strategies (Edited by Jean-François Rioux), Chap. 4. Carleton Univ. Press, Ottawa, Canada (1992).

Robinson, J.P. and Trapp, R., Production and chemistry of mustard gas. In Verification of Dual-use Chemicals under the Chemical Weapons Convention: The Case of Thiodiglycol (Edited by S.J. Lundin), Chap. 2. Oxford Univ. Press, England (1991).

Rothschild, J.H., Tomorrow's Weapons. McGraw-Hill Book Co. New York, 1964.

Ruiz Santoyo, M.E., Gerner, K., Barbiaux Saldaña, M.Y., and Seila, R., Hydrocarbon speciation in Mexico City; initial results, paper presented at 86th Annual Meeting and Exhibition, Air and Waste Management Assoc. Denver, CO (June 13-18, 1993).

Russell, A.G., McRae, G.J., and Cass, G.R., Mathematical modeling of the formation and transport of ammonium nitrate aerosol, Atmos. Environ. 17 (5), 949-964 (1983). 
Sanders, P.F. and Seiber, J.N., Organophosphorus pesticide volatilization. In Long Range Transport of Pesticides (Edited by D.A. Kurtz), p. 17. Lewis Publishers, Chelsea, MI (1984).

Saxena, P., Seigneur, C., and Peterson, T.W., Modeling of multiphase atmospheric aerosols, Atmos. Environ. 17, 1315 (1983).

Schomburg, C.J., Glotfelty, D.E., and Seiber, J.N., Pesticide occurrence and distribution in fog collected near Monterey, California, Environ. Sci. Technol. 25, 155-160 (1991).

Schrader, G., Die Entwicklung Neuer Insektizider Phosphorsaure-Ester. Chemie G.M.B.H., Weinheim, FRG (1963).

Schwartz, W., Chemical characterization of model aerosols, EPA-605/3-74-011, U.S. Environ. Protection Agency (August 1974).

Seiber, J.N., Madden, S.C., McChesney, M.M., and Winterlin, W.L., Toxaphene dissipation from treated cotton field environments: component residual behavior on leaves and in air, soil, and sediments determined by capillary gas chromatography, J. Agric. Food Chem. 27 (2), 284 (1979).

Seiber, J.N., McChesney, M.M., and Woodrow, J.E., Airborne residues resulting from use of methyl parathion, molinate, and thiobencarb on rice in the Sacramento Valley, California, Environ. Toxicol. and Chem. 8, 577-588 (1989).

Seiber, J.N., Wilson, B.W., and McChesney, M.M., Air and fog deposition residues of four organophosphate insecticides used on dormant orchards in the San Joaquin Valley, California, Environ. Sci. Technol. 27, 2236-2243 (1993).

Seiber, J.N. and Woodrow, J.E., Origin and fate of pesticides in air, Proceedings of the Eighth International Congress of Pesticide Chemistry, p. 1054. Washington, DC (1994).

Seinfeld, J.H., Atmospheric Chemistry and Physics of Air Pollution. Wiley \& Sons, New York (1986).

Shih, M.L., Smith, J.R., McMonagle, J.D., Dolzine, T.W., and Gresham, V.C., Detection of metabolites of toxic alkylmethylphosphonates in biological samples, Biol. Mass Spec. 20, 717-723 (1991).

Singh, H.B. and Hanst, P.L., Peroxyacetyl nitrate in the unpolluted atmosphere: an important reservoir for nitrogen oxides, Geophys. Res. Letters 8 (8), 941-944 (1981).

Singh, H.B. and Zimmerman, P., Atmospheric distribution and sources of nonmethane hydrocarbons. In Gaseous Pollutants: Characterization and Cycling (Edited by J.O. Nriagu). Wiley, New York (1992).

Stockholm Int'l. Peace Res. Inst., Chemical Weapons: Destruction and Conversion. Taylor \& Francis Ltd., London (1980).

Sivam,S.P., Hoskins, B., Ho, I.K., An assessment of comparative acute toxicity of diisopropylfluorophosphate, tabun, sarin, and soman in relation to cholinergic and gabaegic enzyme activities in rats, Fundamental and Appl. Toxicology 4 (4), 531-538 (1984). 
Smith, J.R. and Schlager, J.J., Gas-chromatographic separation of the stereoisomers of organophosphorus chemical warfare agents using cyclodextrin capillary columns, J. High Resolut. Chromatogr. 19 (3), 151-154 (1996).

Smith, J.H., Mabey, W.R., Bohomes, N., Holt, B.R., Lee, S.S., Chou, T.W., Bonberger, D.C., and Mill, T., Environmental pathways of selected chemicals in freshwater systems - part II: laboratory studies, 600/7-78-074, U.S. EPA (1978).

Smolarkiewicz, P.K., A simple, positive definite advection scheme with small implicit diffusion, Monthly Weather Rev. 111, 479-486 (1983).

Smolarkiewicz, P.K. and Rasch, P.J., Monotone advection on the sphere: an Eulerian versus semi-Lagrangian approach, J. Atmos. Sci. 48, 793-810 (1991).

Spencer, W.F., Farmer, W.J., and Cliath, M.M., Pesticide volatilization. In Residue Reviews (Edited by F.A. Gunther), V. 49. Springer, New York (1973).

Stelson, A.W., Friedlander, S.K., and Seinfeld, J.H., A note on the equilibrium relationship between ammonia and nitric acid and particulate ammonium nitrate, Atmos. Environ. 13, 369-371 (1979).

Stelson, A.W. and Seinfeld, J.H., Relative humidity and temperature dependence of the ammonium nitrate dissociation constant, Atmos. Environ. 16, 983 (1982a).

Stelson, A.W. and Seinfeld, J.H., Relative humidity and $\mathrm{pH}$ dependence of the vapor pressure of ammonium nitrate-nitric acid solutions at $25^{\circ} \mathrm{C}$, Atmos. Environ. 16, 993 (1982b).

Stockwell, W.R. and Calvert, J.G., The mechanism of the $\mathrm{HO}_{-} \mathrm{SO}_{2}$ reaction, Atmos. Environ. 17, 2231 (1983).

Suzuki, J., Kohno, T., Tsukagosi, M., Furuhata, T., and Yamazaki, K., 18 cases exposed to sarin in Matsumoto, Japan, Internal Medicine 36 (7), 466-470 (1997).

Tang, I.N., Deliquescence properties and particle size change of hygroscopic aerosols. In Generation of Aerosols and Facilities for Exposure Experiments (Edited by K. Willeke), Chap. 7, pp. 153-167. Ann Arbor Science Publishers, Ann Arbor, MI (1980a).

Tang, I.N., On the equilibrium partial pressures of nitric acid and ammonia in the atmosphere, Atmos. Environ. 14, 819 (1980b).

Taylor, G.E. Jr. and Constable, J.V.H., Modeling pollutant deposition to vegetation: scaling down from the canopy to the biochemical level. In Air Pollutants and the Leaf Cuticle (Edited by K.E. Percy, J.N. Cape, R. Jagels, and C.J. Simpson), V. 36. Springer, Berlin (1994).

Taylor, A.W. and Spencer, W.F., Volatilization and vapor transport processes. In Pesticides in the Soil Environment: Processes, Impacts, and Modeling (Edited by H.H. Cheng), Chap. 7 (2), pp. 213-269. Soil Sci. Society of Amer., Inc., Madison, WI (1990).

Temple, P.J. and Taylor, O.C., World-wide ambient measurements of peroxyacetyl nitrate (PAN) and implications for plant injury, Atmos. Environ. 17, 1583 (1983). 
Teske, M.E., Thistle, H.W. Jr., and Barry, J.W., Topics in aerial spray drift modeling. In Environmental Modeling (Edited by P. Zannetti), Chap. 2. Computational Mechanics

Publications, Southhampton, Boston (1996).

Theurer, W., Plate, E.J., and Hoeschele, K., Semi-empirical models as a combination of wind tunnel and numerical dispersion modeling, Atmos. Environ. 30 (21), 3583-3595 (1996).

Tripathi, H.L., Dewey, W.L., and Smith, A.B., Comparison of the effects of diisopropylfluorophosphate, sarin, soman, and tabun on toxicity and brain acetylcholinesterase activity in mice, J. Toxicol. and Environ. Health 26 (4), 437-446 (1989).

Total Security Services Int'1, Inc., Win against terrorism, TSSI, Inc., Centreville, VA (1997).

Tuazon, E.C., Atkinson, R., Aschmann, S.M., Arey, J., Winer, A.M., and Pitts, J.N. Jr., Atmospheric loss processes for 1,2-dibromo-3-chloropropane and trimethyl phosphate, Environ. Sci. Technol. 20, 1043-46 (1986).

Tully, F.P. Ravishankana, A.R., Thompson, R.L., Nicovich, J.M., Shah, R.C., Kreutter, N.M., and Wine, P.H., Kinetics of the reactions of hydroxyl radical with benzene and toluene, J. Phys. Chem. 85, 2262 (1981).

Turco, R.P., Earth Under Siege: From Air Pollution to Global Change. Oxford University Press, Oxford, England (1997).

Turco, R.P., Toon, O.B., and Hamill, P., Heterogeneous physicochemistry of the polar ozone hole, J. Geophys. Res. 94 (D14), 16,493-16,510 (1989).

United Nations, Report of the mission dispatched by the Secretary General to investigate allegations of the use of chemical weapons in the conflict between the Islamic Republic of Iran and Iraq, S/17911, United Nations (March 12, 1986).

U.S. Army, Military chemistry and chemical compounds. In U.S. Army Field Manual 3-9/U.S. Air Force Field Manual 355-7. U.S. Government Printing Office, Washington, DC (Oct. 1975).

Verweij, A. and Boter, H.L., Report Chem. Lab. Toegepast Natuurwet. Onderz, 1976-19 (1976).

Verweij, A., Boter, H.L., and Degenhardt, C.E.A.M., Chemical warfare agents: verification of compounds containing the phosphorus-methyl linkage in waste water, Science 204, 616-618 (May 11, 1979).

Vojvodic', V., Clinical picture, diagnosis, and treatment of poisoning by organophosphate insecticides, Arh. Hig. Rada. 24, 341-355 (1973).

Vojvodic', V. and Binenfeld, Z., Some toxicological problems in the destruction of chemical warfare agents. In Chemical Weapons: Destruction and Conversion, p. 95, Stockholm International Peace Research Institute, Taylor \& Francis Ltd., London (1980).

Volans, A.P., Sarin: guidelines on the management of vicitms of a nerve-gas attack, $J$. Accident \& Emergency Med. 13 (3), 202-206 (1996). 
Wania, F. and Mackay, D., Global fractionation and cold condensation of low volatility organochlorine compounds in polar regions, Ambio 22 (1), 10 (Feb. 1993).

Ward, J.R., Hovanec, J.W,. Albizo, J.M., Szafraniec, L.L., and Beaudry, W.T., Decomposition of phosphonofluoridates on glass, J. Fluorine Chem. 51, 277-282 (1991).

Watson, J.G., Chow, J.C., Lurmann, F.W., and Musarra, S.P., Ammonium nitrate, nitric acid, and ammonia equilibrium in wintertime Phoenix, Arizona, Air \& Waste 44, 405-412 (April 1994).

Whitby, K.T. and Sverdrup, G.M., California aerosols: their physical and chemical characteristics, Adv. Environ. Sci. Technol. 10, 477 (1980).

Wickelgren, I., The big easy serves up a feast to visiting neuroscientists, Science 278, 1404 (Nov. 21, 1997).

Wilson, B.W., Hooper, M.J., Chow, E. et al., Assessment of farm worker risk from organophosphate-induced delayed neuropathy. In Dermal Exposure Related to Pesticide Use, ACS Symposium Series 273, pp. 480-491. Washington, DC (1985).

Wilson, B.W., Hooper, M.J., Littrell, E.E., Detrich, P.J., Hansen, M.E., Weisskopf, C.P., and Seiber, J.N., Orchard dormant sprays and exposure of red-tailed hawks to organophosphates, Bulletin Environ. Contam. Toxicol. 47, 717-724 (1991).

Winer, A.M. and Atkinson, R., Atmospheric reaction pathways and lifetimes for organophosphorus compounds. In Long Range Transport of Pesticides (Edited by D.A. Kurtz), Chap 9. Lewis Publishers, Chelsea, MI (1990).

Wolfe M.F. and Seiber, J.N., Environmental activation of pesticides, Occupational Medicine 8 (3), 561-573 (July-Sept. 1993).

Woodrow, J.E., Crosby, D.G., and Seiber, J.N., Vapor-phase photochemistry of pesticides, Residue Reviews 85, 111-125 (1983).

Woodrow, J.E., Seiber, J.N., Crosby, D.G., Moilanen, K.W., Soderquist, C.J., and Mourer, C., Airborne and surface residues of parathion and its conversion products in a treated plum orchard environment, Arch. Environ. Contam. Toxicol. 6, 175 (1977).

Woodrow, J.E., Seiber, J.N., and Yong-Hwa, K., Measured and calculated evaporation losses of two petroleum hydrocarbon herbicide mixtures under laboratory and field conditions, Environ. Sci. Technol. 20 (8), 783 (1986).

Woodrow, J.E., McChesney, M.M., and Seiber, J.N., Modeling the volatilization of pesticides and their distribution in the atmosphere. In Long Range Transport of Pesticides (Edited by D.A. Kurtz), Chap 5. Lewis Publishers, Chelsea, MI (1990).

Yang, Y.C., Baker, J.A., and Ward, J.R., Decontamination of chemical warfare agents, Chem. Rev. 92, 1729-1743 (1992).

Yasuda, A., Yamaguchi, T., Manabe, Y., Ohkoshi, K., Sakuma, A., and Kusano, Y., Sarin terrorism in Tokyo: 1 year follow-up, Inves. Ophthalmology \& Visual Sci. 38 (4/1), 288 (1997). 
Yokoyama, K., Yamada, A., Mimura, N., Clinical profiles of patients with sarin poisoning after the Tokyo subway attack, Amer. J. Med. 100 (5), 586 (1996).

Yoza, N., Nakashima, S., and Nakazato, T., Enzyme-catalyzed P-F bond hydrolysis of monofluorophosphate as a simple model of sarin detoxification, Chemistry Letters 1, 5354 (1997).

Zabik, J.M. and Seiber, J.N., Atmospheric transport of organophosphate pesticides from California's central valley to the Sierra Nevada Mountains, J. Environ. Qual. 22, 80-90 (1993).

Zapf, P.M., The chemistry of organophosphate nerve agents. In Shadows \& Substance: The Chemical Weapons Convention (Edited by B. Morel and K. Olson), Appendix A. Westview Press, Boulder, CO (1993). 
Table 1. Some urban chem/bio agent release episodes in major cities.

City

Agent Type

Damages

Footnotes

Washington, D.C.

Tokyo, Japan

anthrax

sarin

biologica

anthrax

nerve

biological

hoax

10 deaths

test

1
2
3

1. This hoax was carried out at the offices of the B'nai B'rith. A small container with the incorrectly spelled label "Anthracks" and a small quantity of an involatile liquid caused a large-scale building evacuation and required that emergency decontamination procedures be applied to many of the occupants.

2. The Tokyo sarin release occurred in subway cars and led to 5000 civilian casualties and the deaths of several first-responding employees. Details are given in the text.

3. The rogue cult responsible for the subway sarin incident had been working to develop capabilities to deploy other weapons or nuclear devices and actually tested the release of the biological agent anthrax. 
Table 2. General structures of nerve agents and similar pesticides with the related phosphorus acids (Verweij et al., 1979).

Nerve Agents

\section{Pesticides}<smiles>[X]P(C)(=O)O</smiles><smiles></smiles><smiles>CP(=O)(O)OC(F)(F)Cl</smiles>

(Methylphosphonic)<smiles>[X]P(=O)([O-])[O-]</smiles><smiles>O=P(O)(O)O</smiles>

\section{(Phosphonic)}

Notes: A few pesticides are based on the methylphosphonic acid structure. For sarin, $\mathrm{R}=\mathrm{i}-\mathrm{C}_{3} \mathrm{H}_{7}$ (isopropyl group) and $\mathrm{x}=\mathrm{F}$. For VX, $\mathrm{R}=\mathrm{C}_{2} \mathrm{H}_{5}$ (ethyl group) and

$\mathrm{X}=\mathrm{SCH}_{2} \mathrm{CH}_{2} \mathrm{~N}\left(\mathrm{i}-\mathrm{C}_{3} \mathrm{H}_{7}\right)_{2}$ (Verweij et al., 1979). Note that the relative volatibilities could be estimates qualitatively based on molecular weights. VX is among the most persistent of the nerve gases, being a thick brown oily liquid. The small $\mathrm{X}$ group (a fluorine atom) renders sarin somewhat volatile. 
Table 3. Mechanism of the biological action of organophosphorus esters through inhibition of acetyl choline esterase in the nervous systems of higher animals (Fest \& Schmidt, 1973; Metcalf, 1982; Gearien, 1982). E signifies the enzyme. The pestide form is shown in channel (B).

(A)

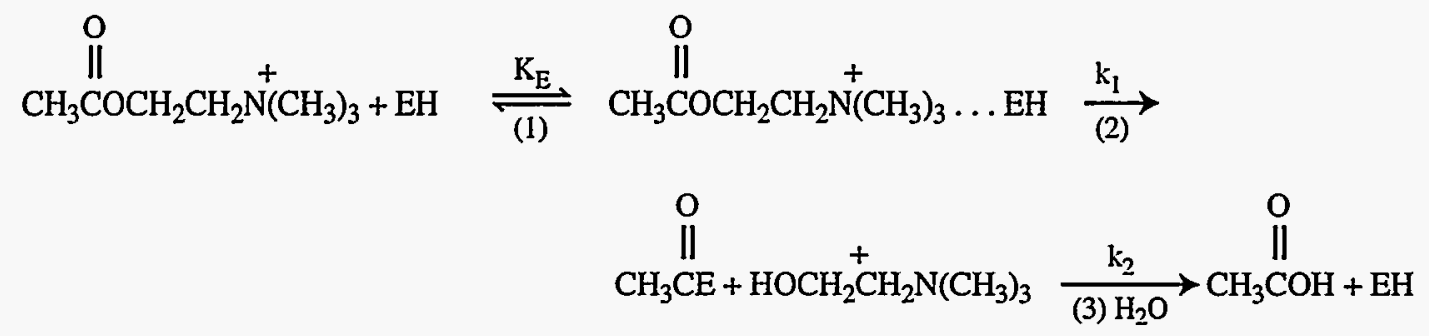

(B)

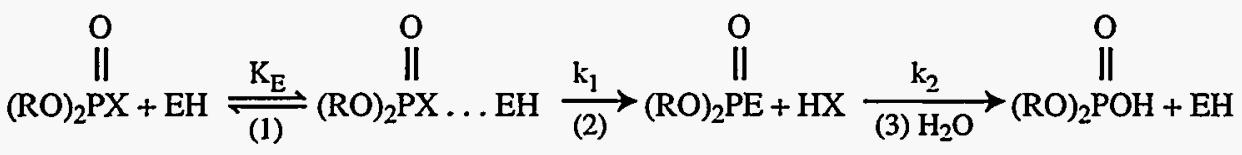


Table 4. Physical and chemical properties of the nerve agents (Harris et al., 1982).

\begin{tabular}{|l|c|c|c|c|}
\hline Property & GA & GB & GD & VX \\
\hline formula wt & 162.13 & 140.10 & 182.18 & 267.38 \\
\hline boiling pt, ${ }^{\circ} \mathrm{C}$ & 246 & 147 & 167 & 298 \\
\hline freezing pt, ${ }^{\circ} \mathrm{C}$ & -50 & -56 & unknown & $<-51$ \\
\hline $\mathrm{d}^{25^{\circ} \mathrm{C}}$ & 1.073 & 1.0887 & 1.0222 & 1.0083 \\
\hline volatility at $25^{\circ} \mathrm{C}, \mathrm{mg} / \mathrm{m}^{3}$ & 610 & 21,900 & 3,060 & 10.5 \\
\hline
\end{tabular}


Table 5. Time scales for parathion oxidations in the atmosphere (Woodrow et al., 1983).

\section{Laboratory}

Field $^{a}$

\begin{tabular}{lclc}
\hline & Half-life (min) & Date & Half-life (min) \\
\hline Light plus ozone & 23 & $6 / 04 / 76$ & $5^{\mathrm{b}}$ \\
Light, no ozone & 41 & $7 / 23 / 75$ & $131^{\mathrm{c}}$ \\
Ozone, no light & 21,060 & & \\
Dark, no ozone & No reaction & & \\
\hline
\end{tabular}

${ }^{2}$ Central Valley of California, USA

${ }^{b}$ At 4:00 p.m.

${ }^{c}$ In the absence of sunlight (9:00 to 10:00 p.m.) 
Table 6. Rate constants for gas-phase reactions of $\mathrm{OH}$ radicals with a series of organophosphorus compounds at $297 \mathrm{~K}$.

$$
\mathrm{k}\left(\mathrm{cm}^{3} \text { molecule }{ }^{-1} \text { second }^{-1}\right)
$$

\begin{tabular}{lc}
\hline Organophosphorus & $10^{12} \times \mathrm{k}_{\mathrm{OH}}$ \\
Compound & $7.37 \pm 0.74$ \\
$\left(\mathrm{CH}_{3} \mathrm{O}\right)_{3} \mathrm{PO}$ & $9.29 \pm 0.68$ \\
$\left(\mathrm{CH}_{3} \mathrm{O}\right)_{2} \mathrm{P}(\mathrm{O}) \mathrm{SCH}_{3}$ & $9.59 \pm 0.75$ \\
$\left(\mathrm{CH}_{3} \mathrm{~S}\right)_{2} \mathrm{P}(\mathrm{O}) \mathrm{OCH}_{3}$ & $69.7 \pm 3.9$ \\
$\left(\mathrm{CH}_{3} \mathrm{O}\right)_{3} \mathrm{PS}$ & $56.0 \pm 1.8$ \\
$\left(\mathrm{CH}_{3} \mathrm{O}\right)_{2} \mathrm{P}(\mathrm{S}) \mathrm{SCH}_{3}$ & $55.3 \pm 3.5$ \\
$\left(\mathrm{C}_{2} \mathrm{H}_{5} \mathrm{O}\right)_{3} \mathrm{PO}$ & $31.9 \pm 2.4$ \\
$\left(\mathrm{CH}_{3} \mathrm{O}\right)_{2} \mathrm{P}(\mathrm{O}) \mathrm{N}\left(\mathrm{CH}_{3}\right)_{2}$ & $46.8 \pm 1.4$ \\
$\left.\left(\mathrm{CH}_{3} \mathrm{O}\right)_{2} \mathrm{P}(\mathrm{S}) \mathrm{N}_{(\mathrm{CH}}\right)_{2}$ & $232 \pm 13$ \\
$\left(\mathrm{CH}_{3} \mathrm{O}\right)_{2} \mathrm{P}(\mathrm{S}) \mathrm{NHCH}_{3}$ & $244 \pm 9$ \\
$\left(\mathrm{CH}_{3} \mathrm{O}\right)_{2} \mathrm{P}(\mathrm{S}) \mathrm{NH}_{2}$ & \pm \\
\hline
\end{tabular}


Table 7. Methane oxidation channels as an example of more general hydrocarbon decay.

$$
\begin{aligned}
& \mathrm{CH}_{4}+\mathrm{OH} \rightarrow \mathrm{CH}_{3}+\mathrm{H}_{2} \mathrm{O} \\
& \mathrm{CH}_{3}+\mathrm{O}_{2} \rightarrow \mathrm{CH}_{3} \mathrm{O}_{2} \\
& \mathrm{CH}_{3} \mathrm{O}_{2}+\mathrm{NO} \rightarrow \mathrm{CH}_{3} \mathrm{O}+\mathrm{NO}_{2} \\
& \mathrm{CH}_{3} \mathrm{O}+\mathrm{O}_{2} \rightarrow \mathrm{CH}_{2} \mathrm{O}+\mathrm{HO}_{2} \\
& \mathrm{NO}_{2}+h v \rightarrow \mathrm{NO}+\mathrm{O} \\
& \mathrm{O}+\mathrm{O}_{2} \rightarrow \mathrm{O}_{3} \\
& \mathrm{HO}_{2}+\mathrm{NO} \rightarrow \mathrm{OH}+\mathrm{NO}_{2} \\
& \mathrm{NO}_{2}+h v \rightarrow \mathrm{NO}+\mathrm{O} \\
& \mathrm{O}+\mathrm{O}_{2} \rightarrow \mathrm{O}_{3} \\
& \mathrm{CH}_{4}+4 \mathrm{O}_{2} \rightarrow \mathrm{CH}_{2} \mathrm{O}+\mathrm{H}_{2} \mathrm{O}+2 \mathrm{O}_{3} \\
& \mathrm{CH}_{2} \mathrm{O}+h v \rightarrow \mathrm{CHO}+\mathrm{H} \\
& \mathrm{H}+\mathrm{O}_{2} \rightarrow \mathrm{HO}_{2} \\
& \mathrm{CHO}+\mathrm{O}_{2} \rightarrow \mathrm{CO}+\mathrm{HO}_{2} \\
& \mathrm{HO}_{2}+\mathrm{NO} \rightarrow \mathrm{OH}+\mathrm{NO}_{2} \\
& \mathrm{HO}_{2}+\mathrm{NO} \rightarrow \mathrm{OH}+\mathrm{NO}_{2} \\
& \mathrm{NO}_{2}+h v \rightarrow \mathrm{NO}+\mathrm{O} \\
& \mathrm{NO}_{2}+h v \rightarrow \mathrm{NO}+\mathrm{O} \\
& \mathrm{O}+\mathrm{O}_{2} \rightarrow \mathrm{O}_{3} \\
& \mathrm{O}+\mathrm{O}_{2} \rightarrow \mathrm{O}_{3} \\
& \mathrm{CH}_{2} \mathrm{O}+4 \mathrm{O}_{2} \rightarrow \mathrm{CO}+2 \mathrm{OH}+2 \mathrm{O}_{3} \\
& \mathrm{CH}_{2} \mathrm{O}+\mathrm{OH} \rightarrow \mathrm{CHO}+\mathrm{H}_{2} \mathrm{O} \\
& \mathrm{CHO}+\mathrm{O}_{2} \rightarrow \mathrm{CO}+\mathrm{HO}_{2} \\
& \mathrm{HO}_{2}+\mathrm{NO} \rightarrow \mathrm{OH}+\mathrm{NO}_{2} \\
& \mathrm{NO}_{2}+h v \rightarrow \mathrm{NO}+\mathrm{O} \\
& \mathrm{O}+\mathrm{O}_{2} \rightarrow \mathrm{O}_{3} \\
& \mathrm{CH}_{2} \mathrm{O}+2 \mathrm{O}_{2} \rightarrow \mathrm{CO}+\mathrm{H}_{2} \mathrm{O}+\mathrm{O}_{3} \\
& \mathrm{CO}+\mathrm{OH} \rightarrow \mathrm{CO}_{2}+\mathrm{H} \\
& \mathrm{H}+\mathrm{O}_{2} \rightarrow \mathrm{HO}_{2} \\
& \mathrm{HO}_{2}+\mathrm{NO} \rightarrow \mathrm{OH}+\mathrm{NO}_{2} \\
& \mathrm{NO}_{2}+h v \rightarrow \mathrm{NO}+\mathrm{O} \\
& \mathrm{O}+\mathrm{O}_{2} \rightarrow \mathrm{O}_{3} \\
& \mathrm{CO}+2 \mathrm{O}_{2} \rightarrow \mathrm{CO}_{2}+\mathrm{O}_{3}
\end{aligned}
$$


Table 8. Midday concentrations of major pollutants in the urban photochemistry and aerosol systems for a first world and developing megacity.

Los Angeles Mexico City

$\begin{array}{lll}\mathrm{NO}_{\mathrm{x}} & 100 \mathrm{ppb} & 250 \mathrm{ppb} \\ \mathrm{NMHC} & 1000 \mathrm{ppbC} & 2000 \mathrm{ppbC} \\ \mathrm{O}_{3} & 150 \mathrm{ppb} & 300 \mathrm{ppb} \\ \mathrm{OH} & 10^{6} \text { to } \geq 10^{7} \mathrm{~cm}^{-3} & 10^{6} \text { to } \geq 10^{7} \mathrm{~cm}^{-3} \\ \text { RSP } & 100 \mu \mathrm{g} \mathrm{m}^{-3} & 200 \mu \mathrm{g} \mathrm{m}^{-3} \\ .01 \text { to } 0.1 \mu & 10^{5} \text { to } 10^{6} \mathrm{~cm}^{-3} & 2 \times 10^{5}-2 \times 10^{6} \mathrm{~cm}^{-3} \\ 0.1 \text { to } 1 \mu & 3 \times 10^{3} \mathrm{~cm}^{-3} & 6 \times 10^{3} \mathrm{~cm}^{-3}\end{array}$


Table 9. Partial (per hydrogen) abstraction rate constants for the attack of hydroxyl radical on organic molecules with different substituents $\mathrm{X}$.

\begin{tabular}{lllllll}
\hline \multicolumn{7}{c}{$\mathrm{X}$ Group } \\
\hline & $\mathrm{ONO}_{2}^{\mathrm{a}}$ & $\mathrm{H}^{\mathrm{b}}$ & $\mathrm{CH}_{3}{ }^{\mathrm{c}}$ & $\mathrm{OH}^{\mathrm{d}}$ & $\mathrm{OCH}_{3}{ }^{\mathrm{e}}$ & $\mathrm{OP}(\mathrm{O})\left(\mathrm{OCH}_{3}\right)_{2}{ }^{1}$ \\
\hline $\mathrm{HCH}_{2}-\mathrm{X}$ & 0.01 & {$[.002]$} & 0.05 & 0.3 & 0.5 & 0.6 \\
$\mathrm{RC}_{2}-\mathrm{X}$ & 0.01 & $0.05^{\mathrm{g}}$ & $0.50^{\mathrm{h}}$ & $1.2^{\mathrm{i}}$ & & \\
$\mathrm{R}_{2} \mathrm{CH}_{\mathrm{H}}-\mathrm{X}$ & 0.13 & $0.50^{\mathrm{h}}$ & $2.0^{\mathrm{j}}$ & $5.0^{\mathrm{k}}$ & & \\
$\mathrm{CH}_{3} \mathrm{CHX}-\mathrm{R}$ & 0.02 & $0.05^{\mathrm{g}, \mathrm{h}}$ & $0.05^{\mathrm{g}, \mathrm{h}}$ & & & \\
$\mathrm{CH}_{3}^{2} \mathrm{CH}_{2} \mathrm{CHX}-\mathrm{R}$ & 0.08 & & & & & \\
\hline
\end{tabular}

a. Data from Gaffney et al. 1986.

b. Methane anomalous, so in brackets.

a-e. All rate constants from Atkinson 1986) unless otherwise stated.

d. We assume abstraction of the alcoholic hydrogen is slow (Demore et al. 1990).

f. Winer and Atkinson (1990).

g. Estimated from ethane and 2,2,3,3 tetramethyl butane.

h. Estimated from propane and 2, 2,3,3 tetramethyl butane.

i. Estimated from ethanol.

j. Estimated from $\mathrm{CH}\left(\mathrm{CH}_{3}\right)_{3}$.

k. Estimated from 2 propanol. 
Table 10. Dissociation constants $\left(\mathrm{K}_{\mathrm{a}} \times 10^{5}\right)$ for benzoic acid derivatives.

$\begin{array}{llccrrr} & \mathrm{H} & \mathrm{CH}_{3} & \mathrm{OCH}_{3} & \mathrm{~F} & \mathrm{Cl} & \mathrm{NO}_{2} \\ \text { o (ortho) } & 6 & 12 & 8 & 54 & 114 & 671 \\ \text { m (meta) } & 6 & 5 & 8 & 14 & 15 & 32 \\ \text { p (para) } & 6 & 4 & 3 & 7 & 11 & 37\end{array}$




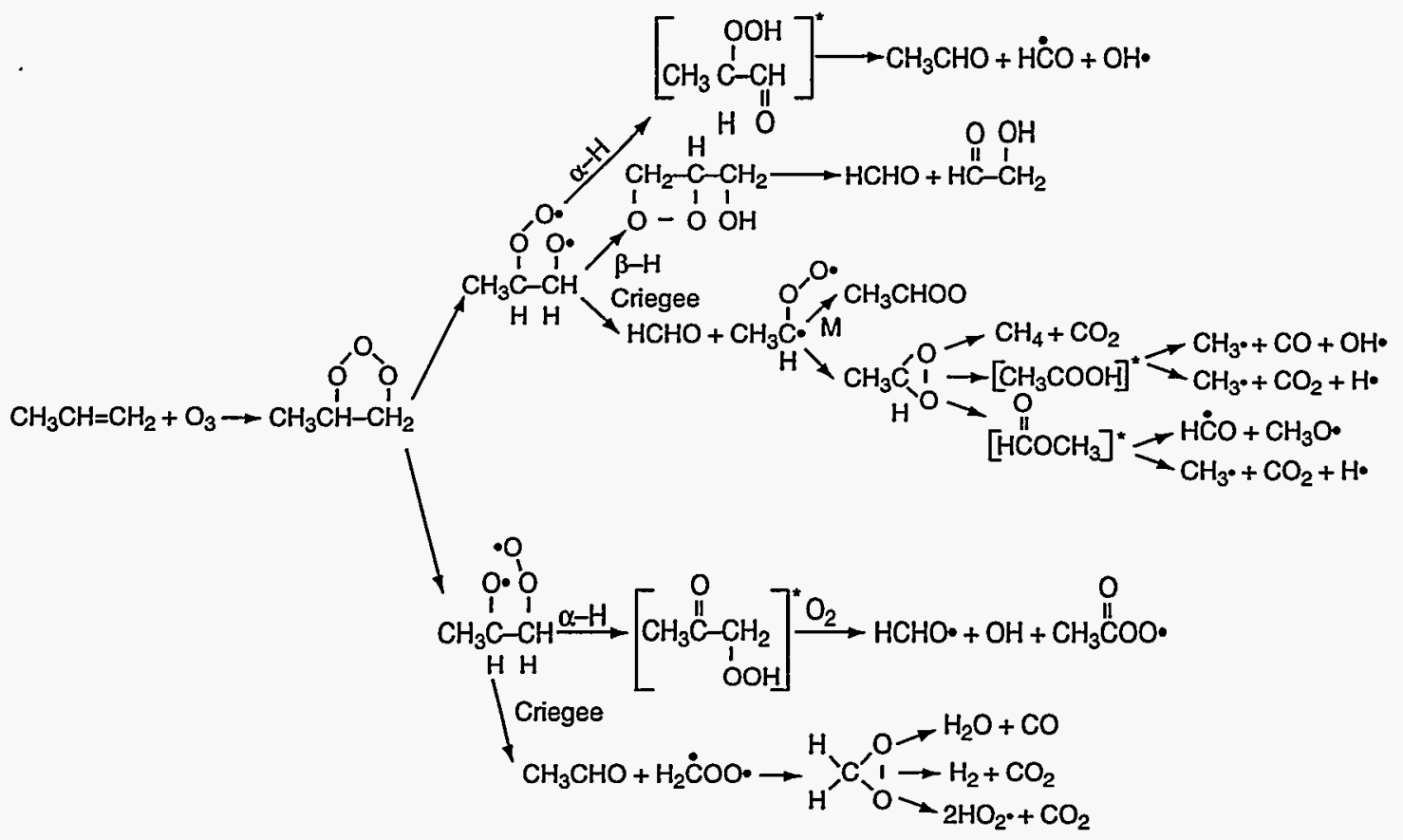

Figure 1. Propylene decay through ozone reaction in the mechanism of Falls and Seinfeld (1978). An analogous chain exists for hydroxyl attack. 

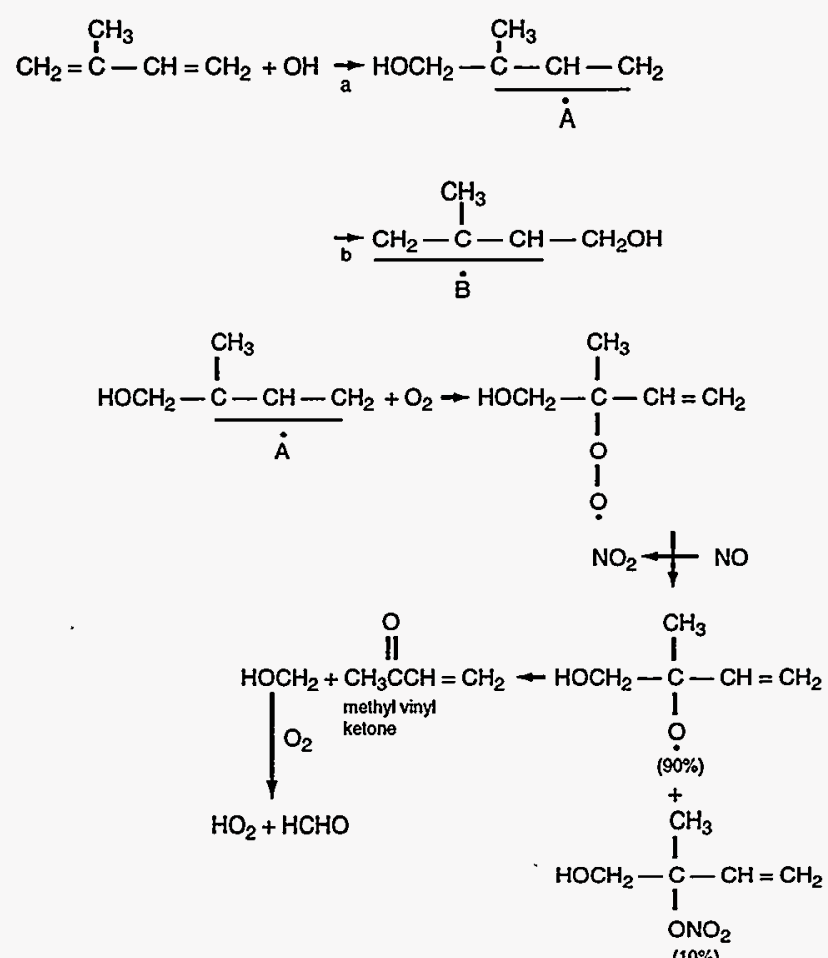

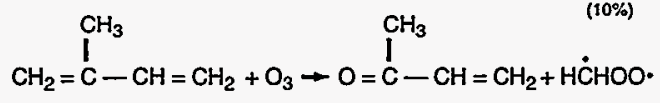

$\mathrm{CH}_{2}=\mathrm{C}_{\mathrm{C}}^{\mathrm{CH}_{3}}-\mathrm{CH}=\mathrm{CH}_{2}+\mathrm{O}_{3} \rightarrow \underset{\text { methacrolein }}{\mathrm{CH}_{2}=\mathrm{C}}-\mathrm{CHO}+\dot{\mathrm{H}} \dot{\mathrm{CHOO}} \cdot$
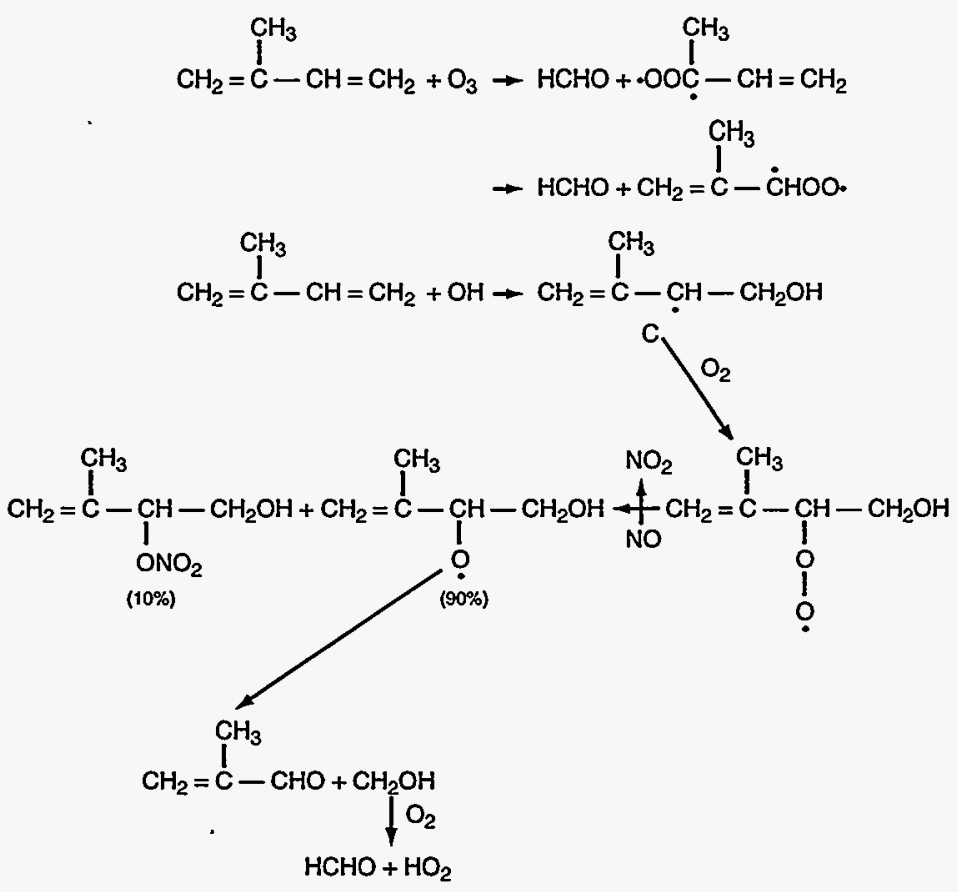

Figure 2. An idealized isoprene decay set for nonurban tropospheric conditions (Niki et al. 1983; Gu et al., 1985; Lloyd et al., 1983). 

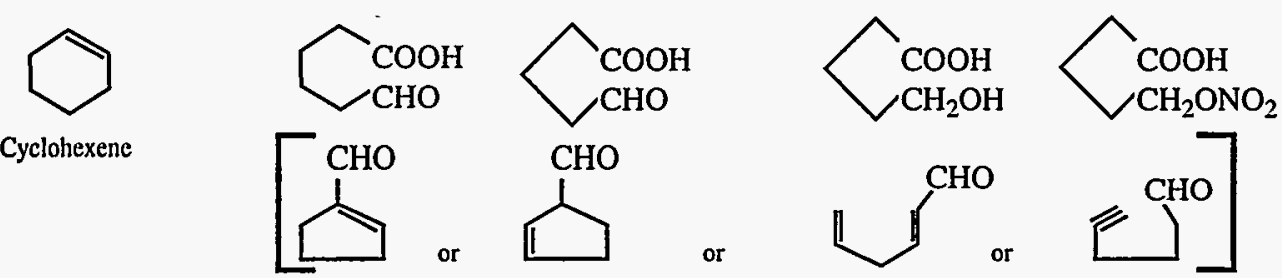

$\overbrace{\text { Toluene }}^{\mathrm{CH}_{3}}$<smiles>O=CC(=CCCO)C(=O)O</smiles><smiles>O=C(O)C(=CCO)C(=O)O</smiles><smiles>O=[N+]([O-])c1ccc(CO)cc1O</smiles><smiles>Cc1cccc([N+](=O)[O-])c1O</smiles><smiles>CC(C=O)/C=C\C=O</smiles><smiles>Cc1cccc(C=O)c1</smiles><smiles>O=CC(=CCO)CO</smiles>
(two isomers)<smiles>C=C(C=O)C=CCC=O</smiles><smiles>CC1=CCC2CC1C2</smiles><smiles>CC(=O)C1C2CCC(C2)C1C(=O)O</smiles><smiles>CC(=O)C1C2CCC1C2C(=O)O</smiles><smiles></smiles><smiles></smiles><smiles>CC(=O)C1C2CCC1(C)C2=O</smiles><smiles>CC1=CCC(C(C)(C)O)CC1=O</smiles><smiles>CC(=O)C(C[C@@H](O)C=O)=C(C)C</smiles>

Figure 3. Particle phase products likely to result from photochemical decay of some cyclic organics in the urban atmosphere (Schwartz, 1974). 

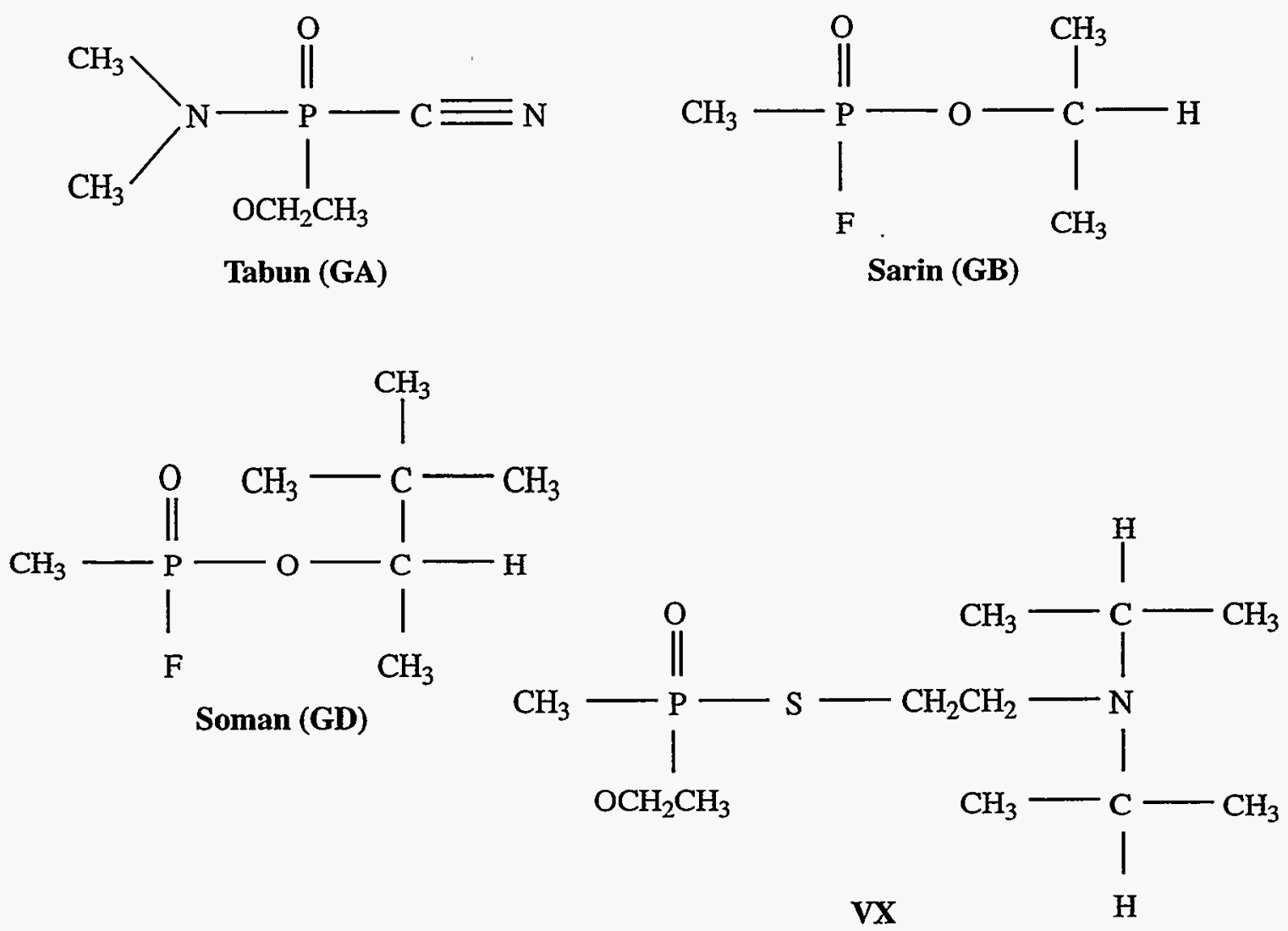

Figure 4. Chemical structures of sarin and some related nerve agents (Dept. of Commerce, 1994). 


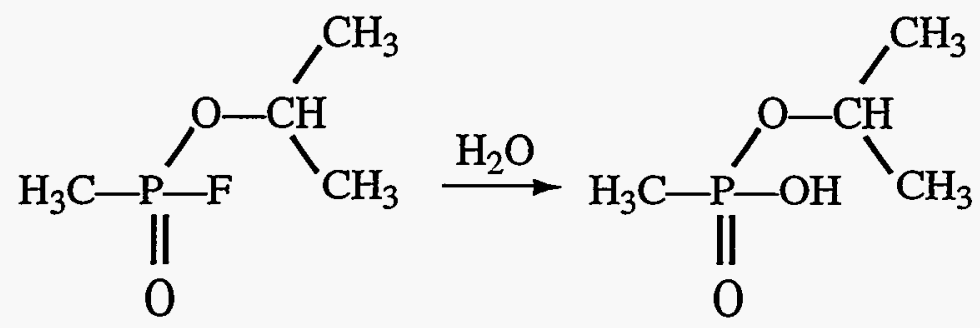

Sarin (GB)

Isopropylmethylphosphonic

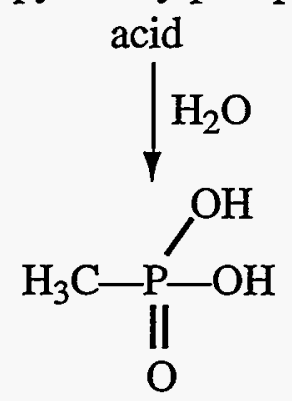

Methylphosphonic acid

Figure 5. Generalized sarin hydrolysis sequence. 


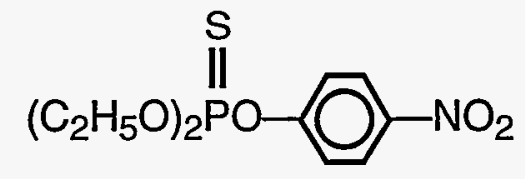

Parathion<smiles>COP(=S)(OC)Oc1ccc([N+](=O)[O-])c(Cl)c1</smiles>

Chlorthion<smiles>CCOC(=S)Oc1[nH]c(Cl)cc1Cl</smiles>

Chlorpyrifos<smiles>CCOP(=S)(OCC)Oc1cc(C)nc(C(C)C)n1</smiles><smiles>CCOC(=O)CC(C(=O)OCC)[P+](=S)OC</smiles>

\section{Malathion}<smiles>COP(=S)(OC)c1ccc([N+](=O)[O-])cc1</smiles>

Methyl Parathion<smiles>COP(=S)(OC)Oc1ccc([N+](=O)[O-])cc1Cl</smiles>

Dicapthon<smiles>COP(C)Oc1ccc(Sc2ccc(OP(=S)(OC)OC)cc2)cc1</smiles>

Temephos<smiles>CO[Pb]S(=S)Cn1nnc2ccccc2c1=O</smiles>

Azinphosmethyl<smiles>CO[PH](=O)C(O)C(C)(C)C</smiles>

Figure 6. Structures of some typical organophosphorus pesticides (Metcalf, 1982 and O'Brien, 1960). 

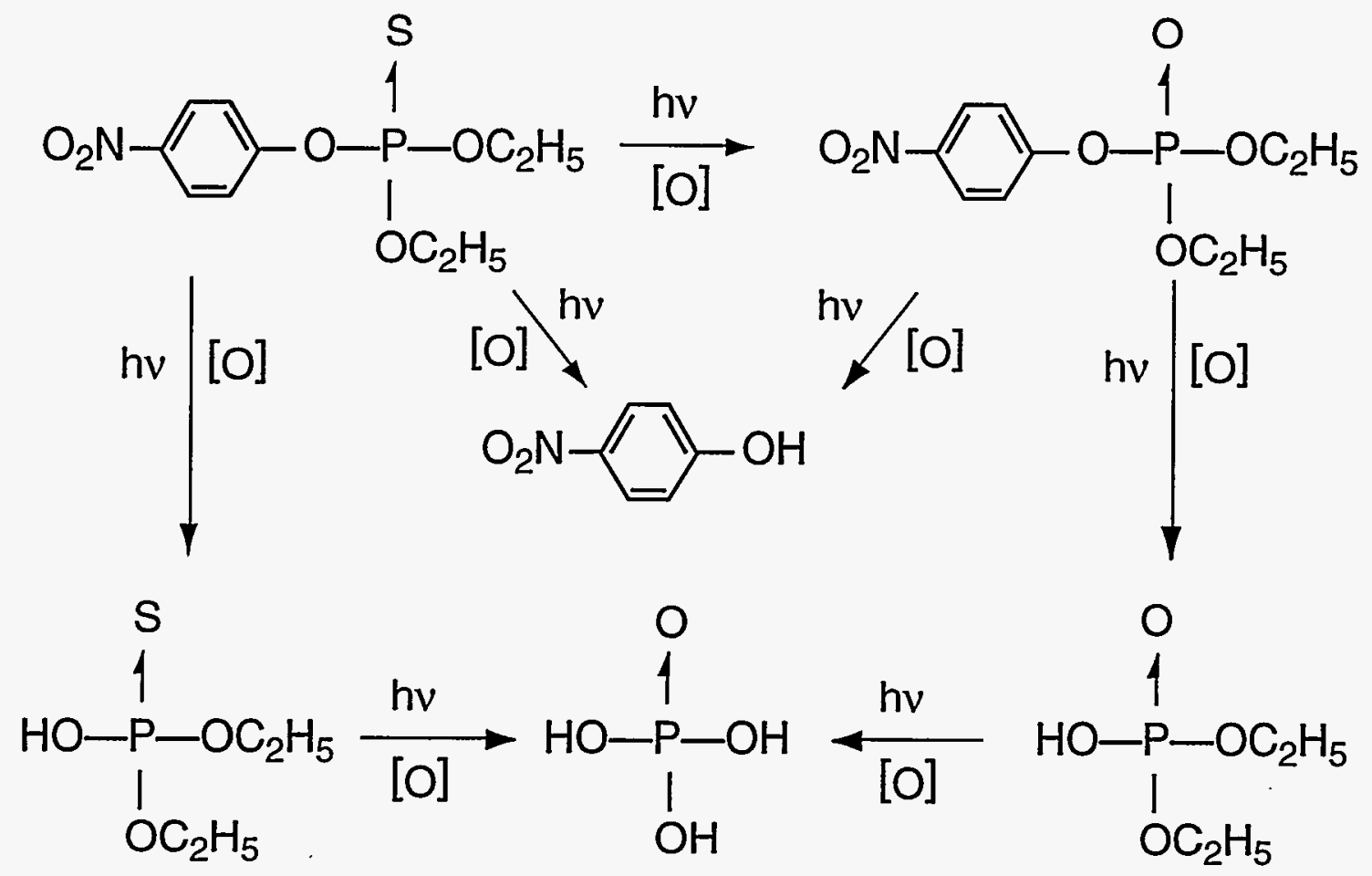

Figure 7. A schematic of daytime atmospheric parathion oxidation (Woodrow et al., 1983). The phosphorus double bond is represented by a single-barbed arrow. 
<smiles>CCO[P+](S)(OCC)Oc1ccc(N(O[P+](S)(OCC)OCC)c2ccc([N+](=O)[O-])cc2)cc1</smiles>

Figure 8. Hydroxl radical attack on parathion may eject p-nitrophenol (Woodrow et al., 1977 and Finlayson Pitts and Pitts, 1986). Here the phosphorus double bond is a doublebarbed arrow. 


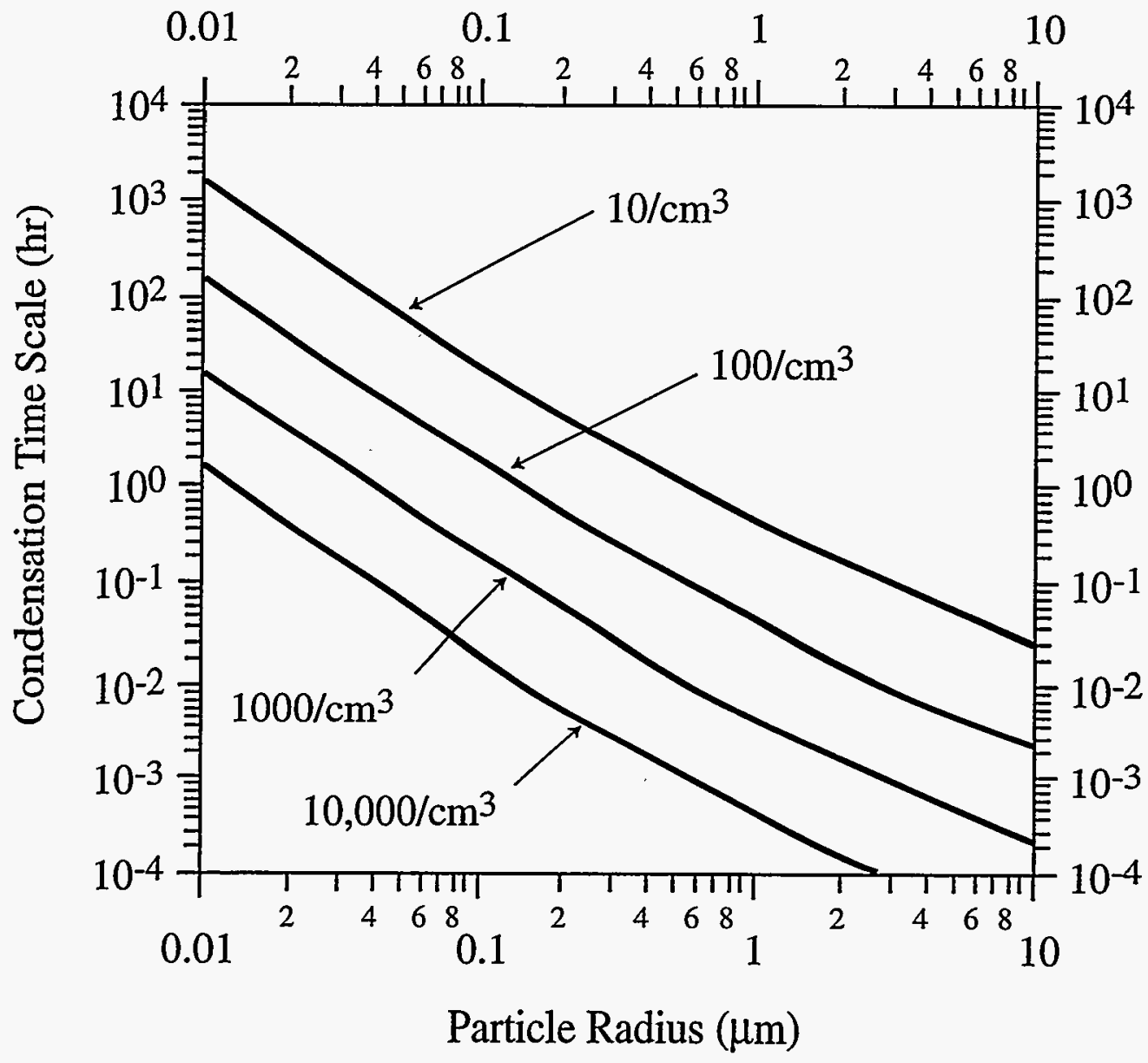

Figure 9. Characteristic time for removal of vapor to particle as a function of radius and aerosol number concentration. 


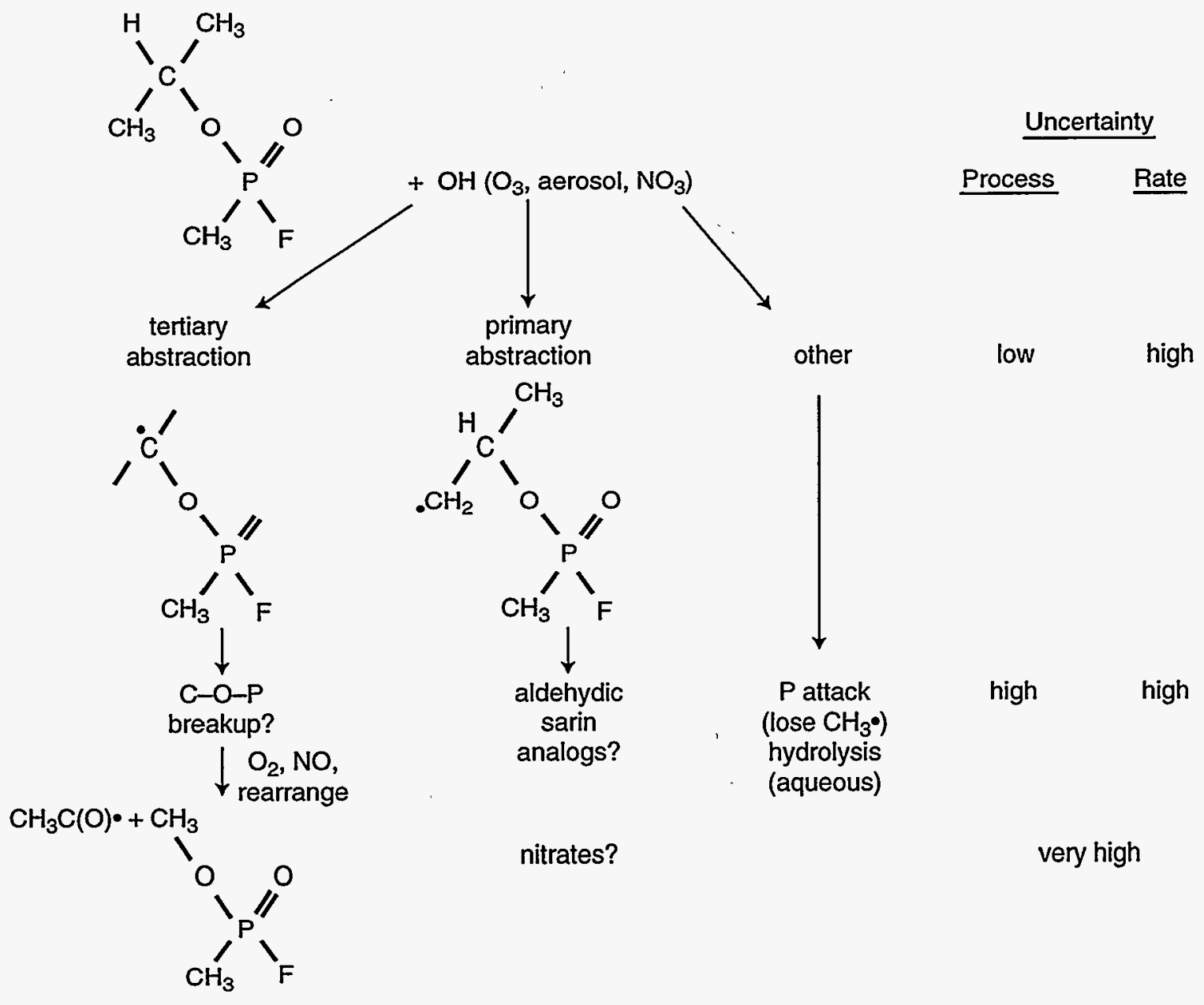

Figure 10. The sarin structure, urban reaction partners presented schematically, and potential degradation pathways. Right hand columns indicate in a qualitative sense the uncertainties inherent in the existence of the processes and their rates at various levels in the diagram. 